\title{
The Role of Southern Ocean Surface Forcings and Mixing in the Global Conveyor
}

\author{
DANIELE IUdiCONE \\ Laboratoire d'Océanographie et du Climat: Expérimentations et Approches Numériques, Unité Mixte de Recherche 7159, \\ CNRS/IRD/UPMC/MNHN, Institut Pierre Simon Laplace, Paris, France, and Stazione Zoologica Anton Dohrn, Naples, Italy, and \\ National Oceanography Centre, Southampton, United Kingdom \\ GURVAN MADEC \\ Laboratoire d'Océanographie et du Climat: Expérimentations et Approches Numériques, Unité Mixte de Recherche 7159, \\ CNRS/IRD/UPMC/MNHN, Institut Pierre Simon Laplace, Paris, France, and National Oceanography Centre, \\ Southampton, United Kingdom \\ BRUno Blanke AND SABRina SPEICH \\ Laboratoire de Physique des Océans, Unité Mixte de Recherche 6523, CNRS/IFREMER/IRD/UBO, Université de Bretagne \\ Occidentale, UFR Sciences, Brest, France
}

(Manuscript received 14 December 2005, in final form 3 July 2007)

\begin{abstract}
Despite the renewed interest in the Southern Ocean, there are yet many unknowns because of the scarcity of measurements and the complexity of the thermohaline circulation. Hence the authors present here the analysis of the thermohaline circulation of the Southern Ocean of a steady-state simulation of a coupled ice-ocean model. The study aims to clarify the roles of surface fluxes and internal mixing, with focus on the mechanisms of the upper branch of the overturning. A quantitative dynamical analysis of the water-mass transformation has been performed using a new method. Surface fluxes, including the effect of the penetrative solar radiation, produce almost $40 \mathrm{~Sv}\left(1 \mathrm{~Sv} \equiv 10^{6} \mathrm{~m}^{3} \mathrm{~s}^{-1}\right)$ of Subantarctic Mode Water while about $5 \mathrm{~Sv}$ of the densest water masses $(\gamma>28.2)$ are formed by brine rejection on the shelves of Antarctica and in the Weddell Sea. Mixing transforms one-half of the Subantarctic Mode Water into intermediate water and Upper Circumpolar Deep Water while bottom water is produced by Lower Circumpolar Deep Water and North Atlantic Deep Water mixing with shelf water. The upwelling of part of the North Atlantic Deep Water inflow is due to internal processes, mainly downward propagation of the surface freshwater excess via vertical mixing at the base of the mixed layer. A complementary Lagrangian analysis of the thermohaline circulation will be presented in a companion paper.
\end{abstract}

\section{Introduction}

The global thermohaline circulation (THC), sometimes referred to as the ocean's conveyor belt (Gordon 1986; Broecker 1987), is responsible for a large portion of the global redistribution of heat, freshwater, and biogeochemical tracers in the present climate. The Southern Ocean plays a major role in the $\mathrm{THC}$ as the main crossroad for the thermohaline circulation (Macdonald and Wunsch 1996; Ganachaud and Wunsch 2000; Rintoul et al. 2001; Sloyan and Rintoul 2001a,b; Talley et al. 2003). It is also the site of large water-mass forma-

Corresponding author address: Daniele Iudicone, Stazione Zoologica “A. Dohrn," Villa Comunale 1, 80121 Naples, Italy.

E-mail: iudicone@szn.it tion and transformation: the wind-driven upwelling of Circumpolar Deep Water (CDW), which exposes the deep-water masses to surface buoyancy fluxes, produces Subantarctic Mode Water (SAMW), Antarctic Intermediate Water (AAIW), and Antarctic Bottom Water (AABW) (e.g., Sverdrup et al. 1942; Tomczak and Godfrey 1994; Schmitz 1996a,b; Speer et al. 2000; Sloyan and Rintoul 2001ab; Blanke et al. 2002; Talley et al. 2003). The definition of main pathways and water properties of the THC has been the focus of large experimental and numerical efforts (e.g., Schmitz 1996b; Sloyan and Rintoul 2001a,b). Notwithstanding these efforts we are still incapable of fully understanding the present and past large-scale oceanic circulation (overturning) and of forecasting future changes, a shortfall that has large implications on our understanding of the 
climate variability (e.g., Knutti et al. 2004). In particular, we need to understand better the dynamics of the water-mass transformations associated with the global thermohaline circulation-water-mass transformations that are driven by air-sea forcing and diapycnal mixing (e.g., Huang 1999; Sloyan and Rintoul 2000; Large and Nurser 2001; Wunsch and Ferrari 2004).

The surface buoyancy fluxes in the Southern Ocean are supposed to be very intense (especially the freshwater component; e.g., Large and Nurser 2001), but in fact they are poorly known. Direct estimates of surface buoyancy fluxes in the Southern Ocean are uncertain because of the large extent of the area that is not covered by meteorological stations or by ship-based measurements (e.g., Josey et al. 1999). As a consequence, also the outputs of atmospheric numerical reanalyses are poorly constrained south of $30^{\circ} \mathrm{S}$. In addition, the freshwater input is supposed to dominate the air-sea buoyancy exchange in this region. The sea ice is a dominant term in the freshwater budget, and it controls the stratification of the upper ocean in the polar regions. Nevertheless, surface flux estimates in standard climatological descriptions do not include the ice-ocean exchanges and they have not been included in previous analyses of water-mass transformations (e.g., Speer et al. 2000; Karstensen and Quadfasel 2002).

Furthermore, the overturn of cold, dense waters into warmer and lighter mode waters (MW) in the Southern Ocean evidently requires a heat gain, but the mechanism of the heat gain has not been identified and its significance with respect to the freshwater gain remains to be established. In particular, as mentioned by Speer et al. (2000), the role of surface heat fluxes in the transformation was not intensely investigated in the past, partly because a high-latitude ocean is expected to lose heat. Toole (1981) suggested that the northward Ekman transport crosses the sea surface isotherms and then provides a heat gain south of the Polar Front. Warren et al. (1996) found a very weak cooling at this latitude plus a stronger gain from the freshwater flux. Taylor et al. (1978) found a net heat gain caused by the variability of atmospheric and oceanic fronts. The Comprehensive Ocean-Atmosphere Dataset (Speer et al. 2000; Large and Nurser 2001; Karstensen and Quadfasel 2002) shows a large buoyancy gain - the strongest heat gain occurring south of Africa. In terms of equivalent water-mass formation (SAMW and AAIW) by surface buoyancy fluxes, Sloyan and Rintoul (2001a) and Speer et al. (2000) propose values in the range of 20-30 $\mathrm{Sv}\left(1 \mathrm{~Sv} \equiv 10^{6} \mathrm{~m}^{3} \mathrm{~s}^{-1}\right)$ whereas Karstensen and Quadfasel (2002) found a value of $75 \mathrm{~Sv}$. Modeling studies gave contrasting results. Numerical studies using simple configurations propose that most of the heat gain oc- curs in the tropics (e.g., Scott and Marotzke 2002; Goodman 1998). A net cooling south of $30^{\circ} \mathrm{S}$ was found by Marsh et al. (2000) in a relatively short GCM simulation $(30 \mathrm{yr})$ in which there was no explicit role for the ice dynamics. Hasumi and Suginohara (1999) used a GCM to suggest that a net heat gain occurs in the Southern Ocean.

Southern Ocean transformations are analyzed here for the information they disclose about basic mechanisms of the meridional circulation. As in Marshall et al. (1999) the aim here is also pedagogic, as it consists of showing how recently developed diagnostic tools allow for a fully consistent and quantitative account of the thermodynamics of the oceanic circulation. The importance of constraining the surface fluxes was underlined by Speer et al. (2000) and Marshall and Radko (2003), for example, who showed in a 2D model of the Southern Ocean how meridional circulation buoyancy fluxes set the meridional overturning and the interior stratification. The meridional circulation is in fact the residual between the Ekman transport and the eddy-driven buoyancy fluxes that are associated with the stratification strength (see also Bryden and Cunningham 2003; Marshall et al. 2006). Despite their success in describing the dynamical balance of the cross-frontal residual circulation and consequent water-mass export, these studies use simplified models of the ocean circulation and thus are unable to account for the frontal dynamics in the Antarctic Circumpolar Current (ACC) system or the thermodynamic transformations occurring during the seasonal cycle of the mixed layer. The latter issue is especially fundamental because the lateral and vertical mixing processes in the mixed layer rectify the meteorological forcings, only communicating seasonally biased properties to the thermocline (Williams et al. 1995). We thus performed a detailed analysis of the dynamics of water-mass transformations in the Southern Ocean in a global ice-ocean model. We will follow, in a broad sense, the systematic approach to the thermodynamics of the North Atlantic circulation presented in Marshall et al. (1999). For the diagnosis of the water-mass formation and transformation we used a quantitative thermodynamic approach recently proposed by Iudicone et al. (2008a, hereinafter IMMD08) that generalizes previous approaches (in particular, Marshall et al. 1999; Large and Nurser 2001). Two different definitions of formation are commonly used: the thermodynamic formation rate in which air-sea fluxes force the fluid to pass laterally across outcropping isopycnals (Walin 1982; Speer and Tziperman 1992; Garrett et al. 1995) and the subduction rate-that is, the rate at which fluid moves from the seasonal boundary layer of the ocean to the interior (Stommel 1979; 
Marshall and Nurser 1992; Marshall et al. 1993; Huang and Qiu 1994). Mixing processes are thus not accounted for in the first approach, and the resulting large discrepancy between the two methods leads to speculations on undefined mixing processes (Tandon and Garrett 1997; Garrett and Tandon 1997; Döös and Webb 1994; Sloyan and Rintoul 2000). Marshall et al. (1999) first defined a unique framework and a common nomenclature by adding the explicit diagnosis of mixing in the mixed layer. IMMD08 recently fully reconciled the two approaches. They included internal buoyancy sources (to account for the solar penetrative irradiance) in the estimates of transformations and introduced a neutral density framework that allows comparison of surface buoyancy fluxes with interior diapycnal fluxes that are far deeper than the range that use of $\sigma_{0}$ would allow for and fully accounting for the nonlinear nature of the equation of state for seawater (McDougall 1987). Therefore, by using the approach in IMMD08 we are able to quantify the role of each component of the dynamics of water-mass transformations in the Southern Ocean in the global model. The study was complemented by a quantitative Lagrangian analysis of the pathways of the THC in the model solution (Iudicone et al. 2008b).

The paper has been divided into sections as follows: model configuration is presented in section 2; main characteristics of the $1500-y r$ solution are presented in section 3; the description of the role of surface buoyancy fluxes and of mixing in creating/destroying water masses forms section 4 and is followed by the discussion (section 5) and conclusions (section 6). The appendix summarizes the theory and the implementation of the diagnosis in IMMD08.

\section{The model}

The ice-ocean coupled model is the "ORCA2"-Louvain-la-Neuve Sea Ice Model (LIM) global configuration (Timmermann et al. 2005). LIM (Fichefet and Morales Maqueda 1997) is a fully dynamical-thermodynamical sea-ice model. The ocean model is the Océan Parallélisé (OPA) model (Madec et al. 1998; Delecluse and Madec 1999) in its global configuration known as ORCA2. The horizontal mesh is based on a $2^{\circ}$ by $2^{\circ}$ Mercator grid, and in the area of interest (i.e., poleward of $30^{\circ} \mathrm{S}$ ) the resolution varies from $\sim 190 \mathrm{~km}$ at $30^{\circ} \mathrm{S}$ to $\sim 40 \mathrm{~km}$ at $80^{\circ} \mathrm{S}$. There are 31 levels in the vertical direction, with the highest resolution $(10 \mathrm{~m})$ in the upper $150 \mathrm{~m}$. The upper boundary uses a free-surface formulation (Roullet and Madec 2000). Lateral mixing is evaluated along isoneutral surfaces. The model is supplemented with the Gent and McWilliams (1990)
TABLE 1. Definition of water masses used in the text.

\begin{tabular}{cc}
\hline Water masses & $\gamma$ \\
\hline TW & $0-26.0$ \\
MW & $26.0-27.2$ \\
IW & $27.2-27.8$ \\
UCDW & $27.8-28.0$ \\
LCDW & $28.0-28.2$ \\
AABW & $28.2-$ bottom \\
\hline
\end{tabular}

parameterization. The lateral mixing coefficient depends on the baroclinic instability growth rate (Treguier et al. 1997). The vertical mixing scheme uses a turbulent closure (Blanke and Delecluse 1993), and there is a diffusive bottom boundary layer parameterization (Beckmann and Döscher 1997). The model background vertical diffusivity increases from the surface to the bottom to mimic the effects of decreased stratification and increased small-scale turbulence near the bottom. (Values ranges from $0.12 \times 10^{-4} \mathrm{~m}^{2} \mathrm{~s}^{-1}$ in the first $1000 \mathrm{~m}$ to $1.2 \times 10^{-4} \mathrm{~m}^{2} \mathrm{~s}^{-1}$ at $5000 \mathrm{~m}$.) Vertical mixing due to convection was parameterized by locally enhancing the vertical diffusivity.

The air-sea fluxes of heat and freshwater (evaporation) are evaluated by means of bulk formulas (Timmermann et al. 2005). A clear-water penetrative shortwave solar radiation formulation is used (Manizza et al. 2005). A restoring to climatological surface salinities was also added. Climatological European Remote Sensing Satellite-1 and -2 scatterometer monthly mean wind stresses were used for the tropics, and the National Centers for Environmental Prediction-National Center for Atmospheric Research climatological dataset was used poleward of $50^{\circ} \mathrm{N}$ and $50^{\circ} \mathrm{S}$. At the bottom, geothermal heating is parameterized as a spatially variable heat source.

Eventually, to ease the analysis, we used neutral densities for classifying water masses (McDougall 1987; Jackett and McDougall 1997); for the sake of simplicity, only six main classes will be discussed (Table 1), defined by combining the analysis of the model watermass properties and the definitions in Sloyan and Rintoul (2001b). Note that the model AAIW is cooler than the in situ data (see section 3), and thus its upper density boundary has been slightly enlarged here.

\section{The thermohaline circulation in the Southern Ocean}

\section{a. The model global solution}

The model global solution has been validated through an extensive comparison with observations (Iu- 

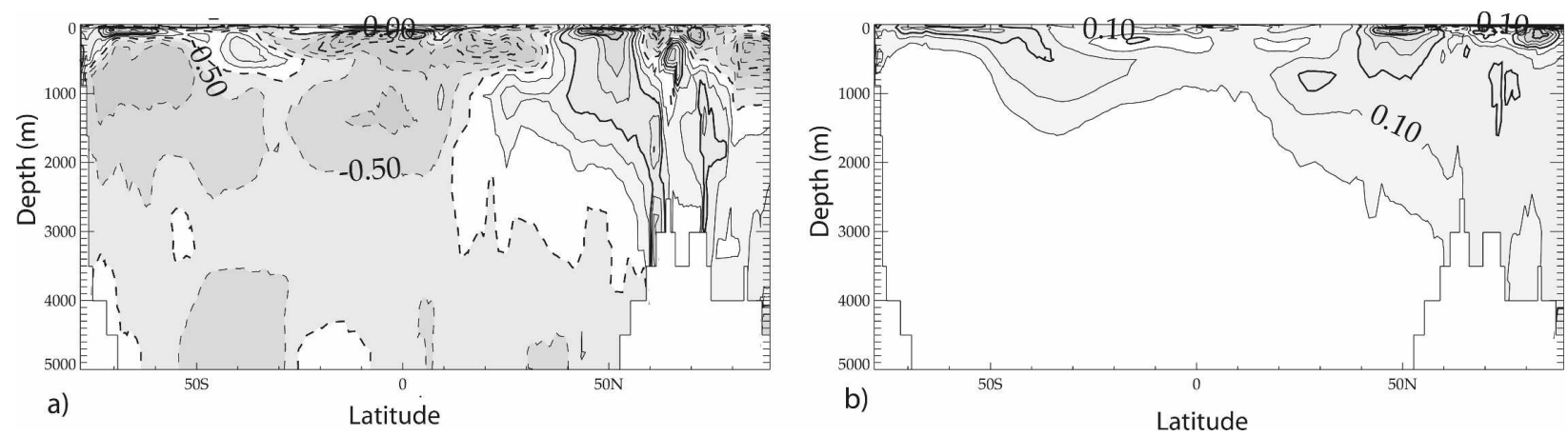

FIG. 1. Anomalies of the model tracer fields with respect to the in situ climatological data from Conkright et al. (1998). (a) Zonally averaged global temperature anomaly (ORCA2-LIM; contour interval: $0.25^{\circ} \mathrm{C}$ ). (b) Zonally averaged global salinity anomaly (ORCA2LIM; contour interval: 0.05 ).

dicone 2007); here we will summarize only the main conclusions.

After a 1500-yr spinup, the drift of model tracers is almost negligible. The model solution presents a net negative bias for the temperature of intermediate and deep water $\left(\sim 0.25^{\circ}-0.5^{\circ} \mathrm{C}\right)$ (Fig. 1$)$. The largest anomalies are in the upper layers of the Antarctic Divergence, in the pycnocline of the equatorial Pacific Ocean, and in the Red Sea Water in the Indian Ocean. Model salinity discrepancy with respect to observations is within 0.1 in most cases (Fig. 1), with slightly larger deviations in the northern high latitudes, at the southern extension of the Mediterranean Water in the Atlantic Ocean and at the subsurface South Pacific Fronts. Last, the middepth Indian Ocean is too fresh because of an insufficient export of Red Sea Water.

The model circulation corresponds well to other OGCM simulations with similar resolutions (e.g., Stammer et al. 2002), including the meridional overturning circulation. The overturning of North Atlantic Deep Water (NADW) in the Atlantic is $\sim 18 \mathrm{~Sv}(\sim 3 \mathrm{~Sv}$ in the Greenland Sea) while the global AABW export is $\sim 10$ Sv with $\sim 3 \mathrm{~Sv}$ in the Atlantic. Transports at main straits and passages are also close to experimental estimates: the Indonesian Throughflow is $\sim 10 \mathrm{~Sv}$ (e.g., Godfrey 1996); the ACC through Drake Passage transports $\sim 148 \mathrm{~Sv}$, only $10 \mathrm{~Sv}$ larger than the most recent observational estimate (Cunningham et al. 2003).

The model global heat transport (not shown) is broadly consistent with previous estimates (e.g., Trenberth and Caron 2001; Ganachaud and Wunsch 2003). At $30^{\circ} \mathrm{S}$ the heat transport is $-0.85 \mathrm{PW}$, that is, within the estimation by Ganachaud and Wunsch (2003) $(-0.6 \pm 0.3 \mathrm{PW})$. The extremes are instead $-1.15 \mathrm{PW}$ at $10^{\circ} \mathrm{S}$ and $1.4 \mathrm{PW}$ at $\sim 20^{\circ} \mathrm{N}$, respectively. The latter estimate is lower than most previous estimates; for instance, Ganachaud and Wunsch (2003) give a northward heat transport at $24^{\circ} \mathrm{N}$ of $1.8 \pm 0.3 \mathrm{PW}$. The over- all pattern of the meridional freshwater transport (not shown) agrees with recent estimates, and at $30^{\circ} \mathrm{S}$ it sums to $\sim 0.7 \times 10^{9} \mathrm{~kg} \mathrm{~s}^{-1}$, close to the estimation of $(0.8 \pm 0.9) \times 10^{9} \mathrm{~kg} \mathrm{~s}^{-1}$ by Ganachaud and Wunsch (2003).

\section{b. The simulated Southern Ocean}

The model capability in reproducing the observed horizontal circulation is crucial for several reasons. One issue of particular importance for this study is that both atmospheric and oceanic climatological datasets contain the fronts that characterize the real ocean. Therefore, because the model surface salinity is explicitly restored to observed values and the air-sea bulk formulas include an implicit restoring term (Haney 1971), mismatches between the forcing climatological datasets and the model surface fields (e.g., a misplacement of the ACC fronts) can flaw the surface buoyancy fluxes. The use of an atmospheric-oceanic coupled model would reduce this problem.

A common definition of the main ACC fronts is based on the temperature field at subsurface. Model annual mean temperatures at $180 \mathrm{~m}$ (not shown) were thus compared with the temperature climatological description of Conkright et al. (1998). Good agreement between the model field and the in situ data was found, but the model's low horizontal resolution affects the reliability of the model circulation downstream of important bottom topographic features, as is the case downstream of the Drake Passage and south and southeast of Australia. The same conclusions were derived from analysis of the annual model sea surface height (SSH) field (Fig. 2), which showed that the model Southern Ocean horizontal circulation is in broad agreement with data except downstream of topographic features. For instance, the Weddell Gyre is observed in both SSH fields, but in the model it is weaker and its northward penetration is underestimated, with a con- 


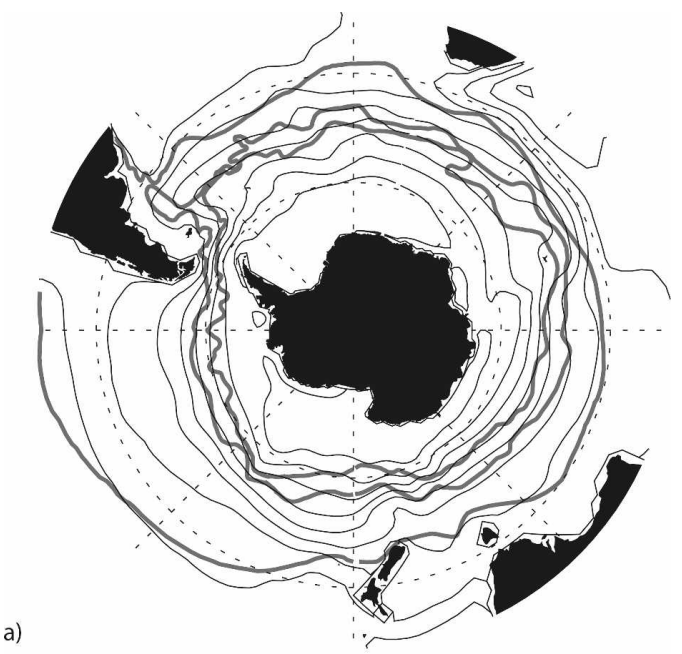

a)

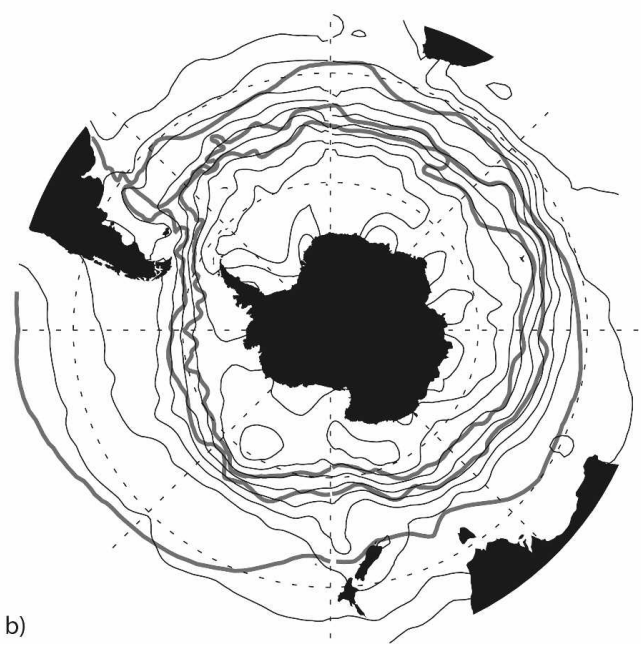

FIG. 2. (a) Annual mean SSH in the model solution. Superimposed are the fronts' mean positions (from Orsi et al. 1995), i.e., moving poleward from $30^{\circ} \mathrm{S}$, the Subtropical Front, Subantarctic Front, and Polar Front. (b) As in (a), but for the model annual mean SSH from Rio and Hernandez (2004).

sequent southward misplacement of the Polar Front (see also Timmermann et al. 2005).

The Southern Ocean annual mean temperature is in good agreement with observations (Iudicone 2007). Although the AABW is definitively cooler than it is in observations, the temperature maximum at depth (upper NADW) is correctly bounded by the model Upper Circumpolar Deep Water (UCDW) density range (Table 1).

The model NADW deep salinity maximum is good in the Lower Circumpolar Deep Water (LCDW) layer (Table 1), but vertical salinity gradients are in general underestimated. Moreover, the salinity mimima associated with the intermediate water (IW) are deeper and denser than in observations. This latter examination
TABLE 2. Model transports (Sv) at $30^{\circ} \mathrm{S}$.

\begin{tabular}{lccr}
\hline \multicolumn{1}{c}{$\gamma$} & Southward & Northward & \multicolumn{1}{c}{ Net } \\
\hline TW & 35.2 & 20.2 & -15.0 \\
MW & 54.5 & 73.9 & 19.4 \\
IW & 35.0 & 38.5 & 3.5 \\
UCDW & 21.8 & 11.6 & -10.2 \\
LCDW & 26.4 & 18.5 & -7.9 \\
AABW & 1.5 & 11.6 & 10.1 \\
\hline
\end{tabular}

justified the change in the AAIW water-mass definition (Table 1) with respect to Sloyan and Rintoul (2001a,b).

The modeled ice cover (Timmermann et al. 2005; Iudicone 2007) is in broad agreement with data. Note that, although the Antarctic summer sea ice extent is found to be in good agreement with observations, a winter maximum is anticipated and the maximum ice extent is about $20 \%$ larger than in observations. Also, sea ice growth and decay are excessively rapid. Last, the surface salinity restoring term can be locally significant $(20 \%-80 \%)$ north of $55^{\circ} \mathrm{S}$ (not shown) because of the misplacement of the fronts, whereas it is more uniform (and thus less significant) poleward of $55^{\circ} \mathrm{S}$ (see also section 4).

\section{c. The overturning in the Southern Ocean}

The model upper-ocean ventilation is similar to observational estimates and is discussed in Iudicone et al. (2008b). Net model budgets at $30^{\circ} \mathrm{S}$ are characterized by a shallow overturning of subtropical waters into MW and a deep overturning of deep waters into bottom waters (Tables 2 and 3). This pattern compares reasonably well to inverse models (e.g., Macdonald and Wunsch 1996; Ganachaud and Wunsch 2000; Sloyan and Rintoul 2001a,b; Wijffels 2001); it compares better to the data analyses of Talley et al. (2003) and Talley (2003), which present a more detailed analysis of the upper cell [thermocline water (TW) and MW]. This shallow overturning in the model is associated with a large horizontal transport ( $\sim 90 \mathrm{~Sv} ; 80 \mathrm{~Sv}$ in Sloyan and Rintoul 2001b); MW net formation is 2 times that found in Talley (2003). AAIW transports are large ( $\sim 35 \mathrm{~Sv})$, but AAIW net production is only $3-4 \mathrm{~Sv}$, as in all of the experimental estimates. Deep and bottom transports vary greatly in experimental estimates; nevertheless, model deep and bottom net transports $(\sim 10 \mathrm{~Sv})$ are much weaker than most of the experimental estimates.

To be more specific, the model Pacific Ocean basin gains MW/IW and AABW (Table 3) while feeding the Southern Ocean CDW layers, where CDW is the ensemble of UCDW and LCDW. Net transports compare well to Talley et al. (2003), but model MW/IW northward transports are 2 times as large, CDW southward 
TABLE 3. Model transports (Sv) at $30^{\circ} \mathrm{S}$ for each main subbasin.

\begin{tabular}{|c|c|c|c|c|c|c|c|c|c|}
\hline \multirow[b]{2}{*}{$\gamma$} & \multicolumn{3}{|c|}{ Pacific } & \multicolumn{3}{|c|}{ Indian } & \multicolumn{3}{|c|}{ Atlantic } \\
\hline & Southward & Northward & Net & Southward & Northward & Net & Southward & Northward & Net \\
\hline TW & 14.4 & 12.6 & -1.8 & 18.1 & 5.0 & -13.1 & 2.6 & 2.6 & - \\
\hline MW & 14.1 & 21.3 & 7.2 & 31.4 & 34.1 & 2.7 & 9.0 & 18.5 & 9.5 \\
\hline IW & 10.9 & 13.2 & 2.3 & 17.2 & 14.0 & -3.2 & 6.9 & 11.3 & 4.4 \\
\hline UCDW & 6.7 & 4.1 & -2.6 & 5.3 & 4.5 & -0.8 & 9.7 & 3.0 & -6.7 \\
\hline LCDW & 7.0 & 7.4 & 0.4 & 5.3 & 7.4 & 2.1 & 14.1 & 3.7 & -10.4 \\
\hline AABW & 0.1 & 6.4 & 6.3 & 0.9 & 1.9 & 1.0 & 0.5 & 3.3 & 2.8 \\
\hline
\end{tabular}

flow is only one-half, and AABW northward flow is $30 \%$ weaker. In comparison with Sloyan and Rintoul (2001b), the IW net transport is similarly small; it is similar in its northward flow of $\sim 10 \mathrm{~Sv}$. Sloyan and Rintoul (2001b) propose the existence of an intense UCDW/LCDW cell $(\sim 20-25 \mathrm{~Sv})$ that is absent in the model and is much weaker in Talley et al. (2003).

The model Southern Ocean in the Indian Ocean sector (Table 3) is characterized by a large net loss of TW, a small IW deficit, and small gains for the other water masses. Summing up TW and MW imports, we obtained the value in Talley et al. (2003) $(\sim 11 \mathrm{~Sv})$ but the MW export is closer to estimates in Robbins and Toole (1997), and in Toole and Warren (1993). Sloyan and Rintoul (2001b) propose a slightly negative MW budget. A net northward transport of IW is consistent with the most recent studies (Sloyan and Rintoul 2001b; Talley et al. 2003). The deep cell is largely underestimated here (e.g., Talley et al. 2003). Bottom-water transport is $1 \mathrm{~Sv}$ in the model and in Talley et al. (2003), Robbins and Toole (1997), and Warren (1993); it sums up to $10 \mathrm{~Sv}$ in Sloyan and Rintoul (2001b; see their paper for a discussion).

The Atlantic Ocean sector in the model (see Table 3) loses MW/IW and AABW and gains UCDW/LCDW (i.e., NADW). The agreement with Talley et al. (2003) is noticeable: the MW/IW is $14 \mathrm{~Sv}$ in the model and 12.6 $\mathrm{Sv}$ in Talley et al. (2003), the NADW/CDW is $17.1 \mathrm{~Sv}$ in the model and 17.8 Sv in Talley et al. (2003), and AABW is $2.8 \mathrm{~Sv}$ in the model and $3.8 \mathrm{~Sv}$ in Talley et al. (2003). Good agreement is found also with Sloyan and Rintoul (2001b), the main difference being in their larger (6 Sv) AABW export.

Last, the model circulation has been validated by comparing offline simulations of transient tracers and World Ocean Circulation Experiment (WOCE) results (Iudicone 2007). In particular, the simulated chlorofluorocarbon inventories reveal a marked improvement over similar models (Ocean Carbon-Cycle Model Intercomparison Project; Dutay et al. 2002). Model inventories are in excellent agreement with Atlantic and Pacific Ocean WOCE inventories, but the Indian Ocean sector ventilation is overestimated by a factor of 2 .
In summary, although the model is in good agreement with observations, some discrepancies could greatly affect the results: in particular, the (dramatic) underestimation of the deep overturning could affect the analysis of the water-mass pathways, the misplacement of ACC fronts in some regions could affect the air-sea flux estimates, and the overestimation of the MW ventilation in the Indian Ocean sector could affect the estimates of the transformations associated with the shallow overturning.

\section{The thermodynamics of the model Southern Ocean thermohaline circulation}

\section{a. Surface buoyancy fluxes}

Model zonal mean density fluxes (Fig. 3) are essentially positive between $20^{\circ}$ and $43^{\circ} \mathrm{S}$, mainly because of large heat losses. The fluxes become negative south of $43^{\circ} \mathrm{S}$, as in most of the recent climatological datasets (e.g., Large and Nurser 2001). In particular, in the $43^{\circ}$ $53^{\circ} \mathrm{S}$ latitudinal band, heat and freshwater terms are of the same order. Poleward of $55^{\circ} \mathrm{S}$ a slight cooling is observed, overwhelmed by the large freshwater input. Brine rejection causes a large buoyancy loss along the coasts of Antarctica. Last, the role of the restoration of surface salinity is significant, but it is evenly distributed and in no case is critical.

The geographical distribution of the surface density fluxes is shown in Fig. 4. The patterns compare well to previous estimates from climatological data (da Silva et al. 1994a,b; Zhang and Talley 1998; Karstensen and Quadfasel 2002; see also Marsh et al. 2000). They present a predominance of large positive density fluxes along the southern extensions of the western boundary currents that are due to intense heat losses. A large band of excess precipitation is observed around $40^{\circ} \mathrm{S}$ in the Pacific, and at $\sim 50^{\circ} \mathrm{S}$ precipitation excesses are observed in the central South Atlantic and south of Australia. The coastal polynyas in the Ross Sea, in the Weddell Sea, and along the Indian Ocean sector of Antarctica produce local maxima in the total and freshwater fluxes. Note that south of $50^{\circ} \mathrm{S}$ the heat flux is 


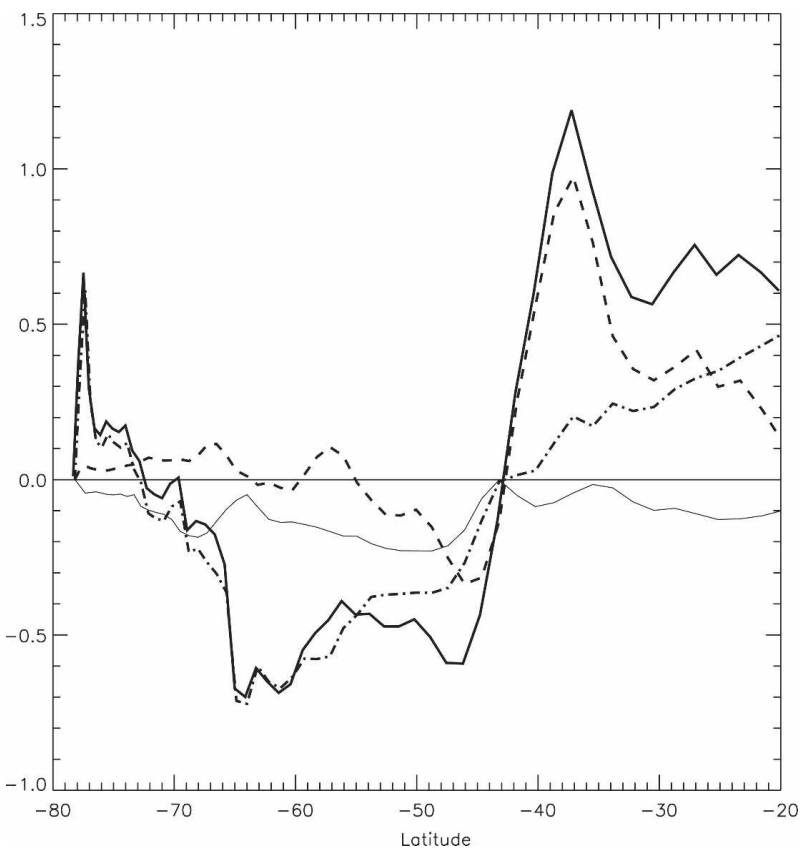

FIG. 3. Surface density fluxes $\left(10^{-6} \mathrm{~kg} \mathrm{~m}^{-2} \mathrm{~s}^{-1}\right)$ : total density flux (thick solid line); heat-driven density flux (dashed line); freshwater-driven density flux (dotted-dashed line); and density flux due to the surface salinity restoring (thin solid line).

uniformly close to zero or is slightly positive and the buoyancy flux is dominated by the freshwater component. As in most studies, here polar regions are thus characterized by a buoyancy gain from the atmosphere, because the freshwater input largely dominates the net buoyancy flux (see also Speer et al. 2000). The absence in the model of a net heat gain in polar regions is nevertheless a major discrepancy with some previous estimates (e.g., Karstensen and Quadfasel 2002), but the sign of the net heat flux in these regions actually depends on the climatological data used for estimating the meteorological forcing, as discussed by Karstensen and Quadfasel (2002). In the case of the model, the southward displacement of the ACC fronts east of the Drake Passage and the northward displacement east of New Zealand imply anomalous heat fluxes of opposite signs; that is, the first implies an overcooling of surface waters while the contrary occurs in the second case.

Dianeutral fluxes due to air-sea and ice-sea interactions in the Southern Ocean, computed using Eq. (A4), are shown in Fig. 5a. (The corresponding formation rates $M$ are the convergence/divergence of the dianeutral transports, i.e., the slope of the curves in Fig. 5.) In our simulation $\sim 12 \mathrm{~Sv}$ of TW become denser MW through a heat loss. A negative-buoyancy input, due to freshwater excess, largely dominates the dianeutral flux at higher densities $(27.0<\gamma<28.0)$ in which $\sim 15 \mathrm{~Sv}$ of IW and $\sim 15 \mathrm{~Sv}$ of UCDW are transformed into MW.
The slope of the net transformations is positive for IW (cooling) and UCDW (freshwater gain), which are thus destroyed. The convergence of TW and IW/UCDW finally produces more than $40 \mathrm{~Sv}$ of MW. The LCDW layer is not significantly involved in the surface transformations. The computation of the surface fluxes occurring south of $42^{\circ} \mathrm{S}$ (Fig. 5b; see Large and Nurser 2001) shows that a net heat gain characterizes the SAMW production, masked in Fig. 5a by the intense cooling experienced by TW in the subtropics.

About $5 \mathrm{~Sv}$ of extremely dense Antarctica shelf water converge into the AABW class. The effect of the brine rejection dominates this transformation (Fig. $5 \mathrm{a} ; \sim 5 \mathrm{~Sv}$ in the highest densities). The flux at the ice-ocean surface (Fig. 5c) shows how the brine rejection forms the densest water masses and the seasonal ice melting, which freshens the lighter UCDW and does not compensate it. Last, the geothermal flux at the bottom retransforms $1 \mathrm{~Sv}$ of AABW into LCDW (not shown).

The estimates of the water-mass transformations due to surface forcings in Fig. 5a cannot be directly compared with previous results because the sea-ice buoyancy fluxes and the air-sea interactions in the coastal polynyas were included in neither the data analysis, because of a lack of in situ measurements, nor in previous model results. In fact, previous estimates of surface water-mass formation present no data for large densities because in situ data are biased toward summer values [e.g., the maximum density in Karstensen and Quadfasel (2002) is merely 27.3, the AAIW density]. Furthermore, all but Sloyan and Rintoul (2001a,b) used a surface-referenced potential-density framework that does not allow for a proper assessment of the densest water-mass transformations (IMMD08). More important, they are strongly dependent on the atmospheric climatological datasets: the net MW and IW formation estimate varies from 20 to $70 \mathrm{~Sv}$ depending on the dataset, the diapycnal flux between TW and MW varies from -10 to $30 \mathrm{~Sv}$, and the conversion of dense water into MW/IW varies from 0 to $75 \mathrm{~Sv}$ (K. Speer, 2006, personal communication). Nevertheless, the overall pattern of the water-mass transformations due to surface forcings, the densification (cooling) for mode waters, and the lightening (freshening) for AAIW and water is coherent with previous analyses of existing datasets (e.g., Large and Nurser 2001; Speer et al. 2000; Karstensen and Quadfasel 2002). In particular, the net production of mode and intermediate waters compares well to estimates in Sloyan and Rintoul (2001a), and the mode water production is several Sverdrups lower than the mode water production in Karstensen and Quadfasel (2002; see also section 5). For the largest densities, using geochemical tracer budgets, Orsi et al. (2001) esti- 

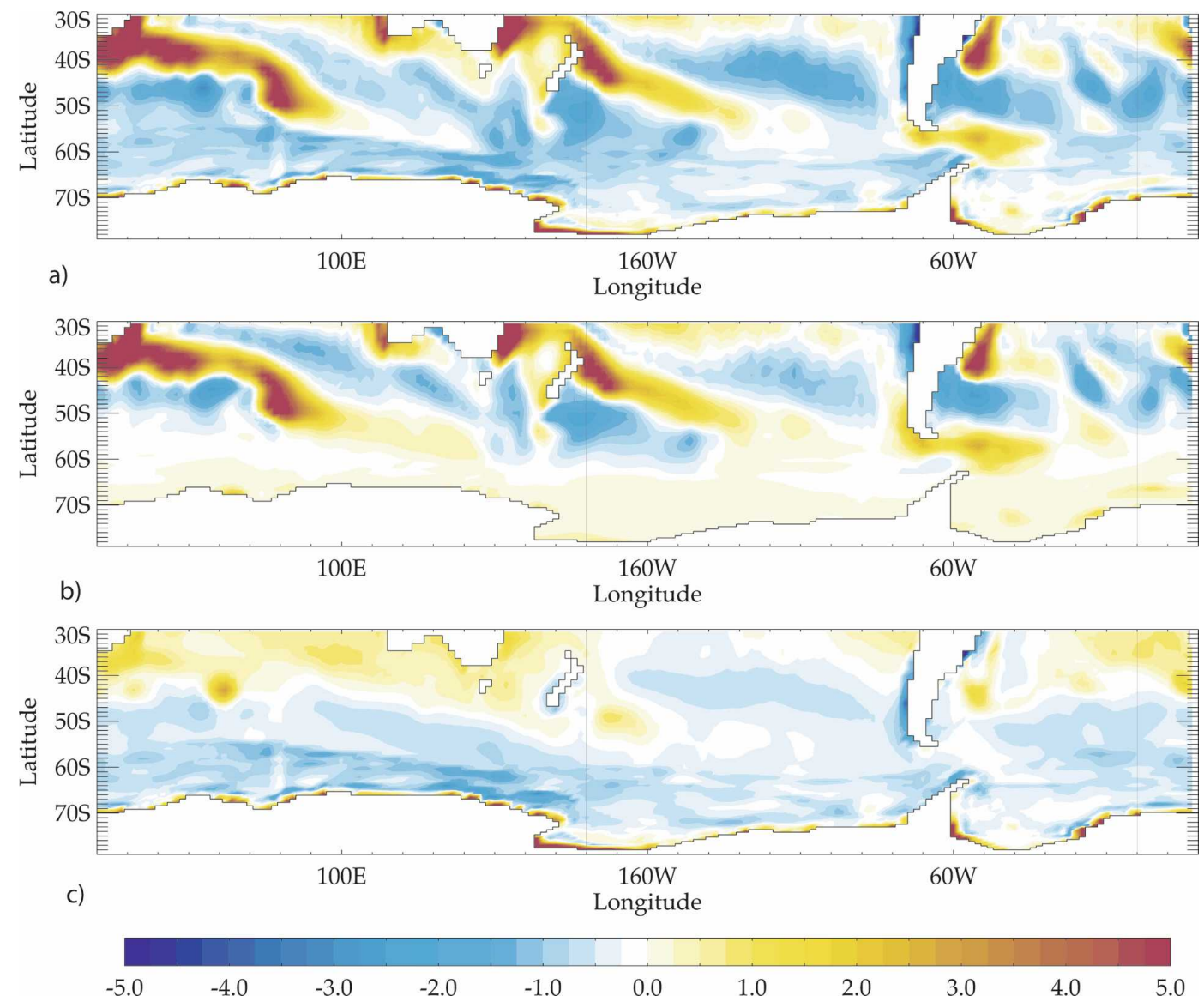

FIG. 4. Surface density flux $\left(10^{-6} \mathrm{~kg} \mathrm{~m}^{-2} \mathrm{~s}^{-1}\right)$. (a) Total surface fluxes, (b) the thermal component, and (c) the freshwater component.

mated the ventilation of AABW on shelves of Antarctica to be $\sim 5 \mathrm{~Sv}$, that is, close to the estimate here presented. The net buoyancy gain for AAIW and UCDW in our model is definitively larger than in previous ocean-only model results (e.g., Marsh et al. 2000).

\section{b. The role of mixing and advection in the water-mass transformations}

The role of mixing in the water-mass transformations has rarely been discussed quantitatively in the past because mixing is difficult to measure in situ and is heavily parameterized in ocean models, especially in the case of global models. We will address this issue here because it is indeed necessary to allow full exploitation of ocean modeling. Nevertheless, the results depend heavily also on mixing parameterizations (not only on parameterizations, however, because mixing, e.g., is also the result of the model dynamical adjustment to forcings). One particular issue that is rarely discussed is that recent low-resolution $z$-coordinate models split the mixing into "lateral" (or isopycnal) and "vertical" components.
This distinction becomes obviously ill defined in the upper-water column because isopycnals are displaced vertically in the mixed layer. In practice, to avoid numerical instabilities and to mimic the diapycnal transport due to surface eddy activity, the model lateral mixing becomes progressively horizontal close to the surface (reference surfaces are flattened) and thus the isopycnal mixing is in fact diapycnal there. As a consequence, one main concern about the following results is that the flattening occurs at fixed $z$ levels while the model mixed layer can have a large vertical excursion; that is, the diapycnal mixing due to the model lateral mixing could be overestimated.

The role of mixing in the water-mass transformations is frequently evaluated as the residual between horizontal transports across the domain boundary and the surface diapycnal fluxes. Following the approach of Marshall et al. (1999) and IMMD08, we use a more quantitative and physically informative approach. First, the net contribution of the Southern Ocean to the global thermohaline circulation is evaluated by summing up 

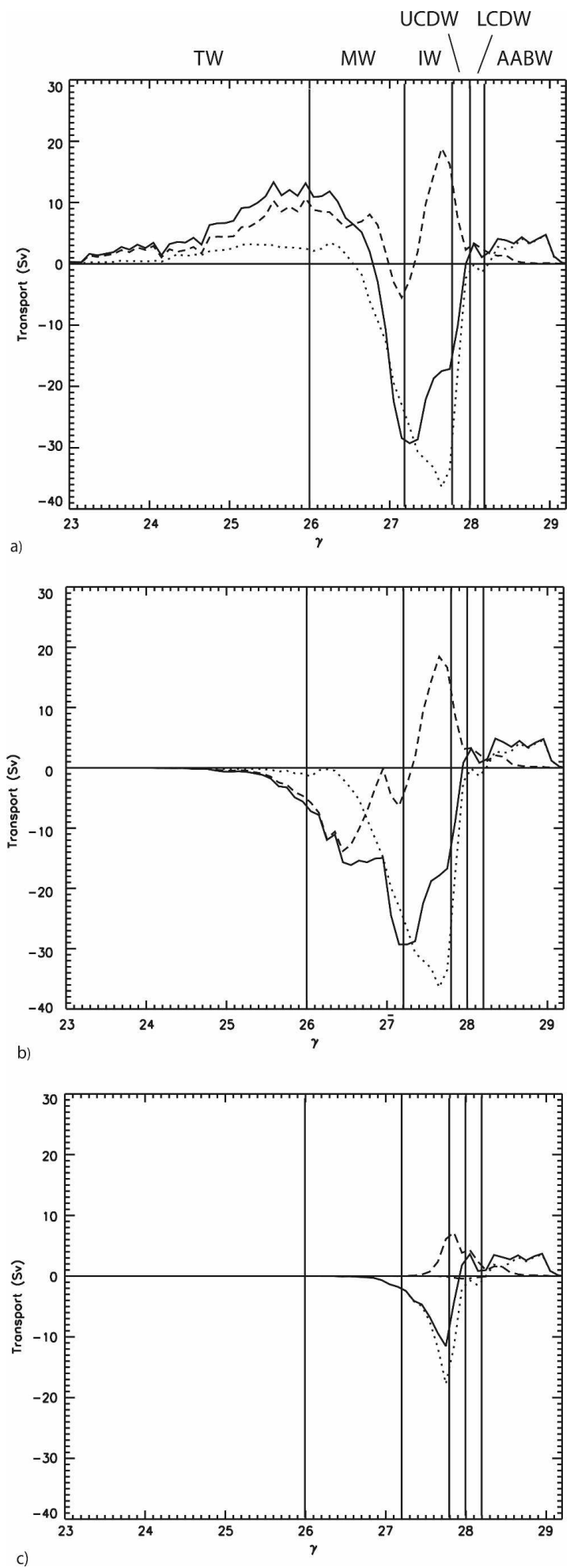

FIG. 5. (a) Surface dianeutral fluxes poleward of $30^{\circ} \mathrm{S}(\mathrm{Sv})$ : total transport (solid line), the heat component (dashed line), and the freshwater component (dotted line). The vertical lines are the water-mass boundaries in Table 1 . As in the classical formulation, positive (negative) values indicate that surface fluxes are transforming surface water into higher (lower) density classes. (b) Values for the region between $42^{\circ} \mathrm{S}$ and Antarctica. (c) Surface dianeutral fluxes at the ice-ocean interface.

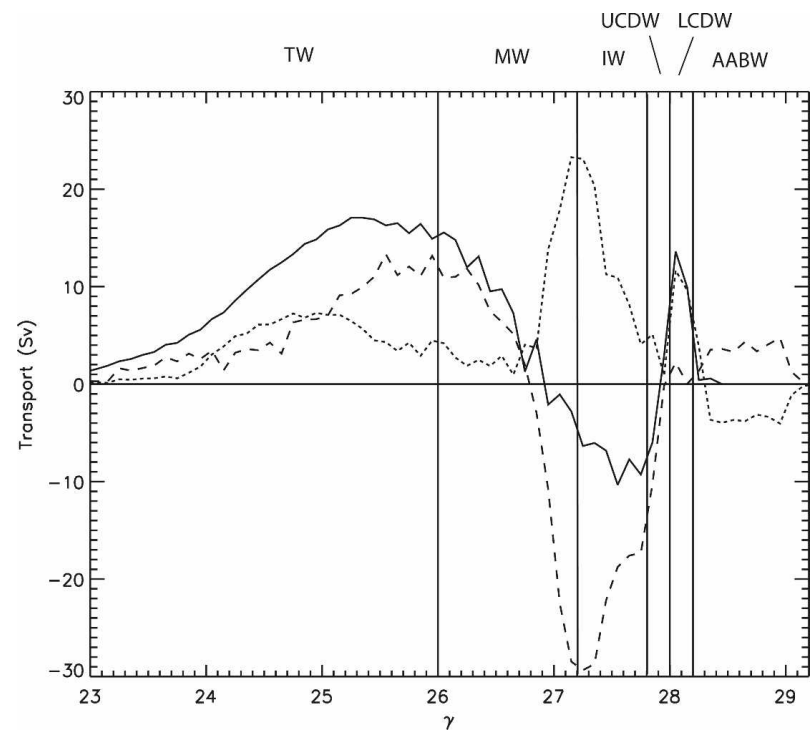

FIG. 6. Surface dianeutral fluxes (dashed line), net transformations at $30^{\circ} \mathrm{S}$ (solid line), and dianeutral fluxes due to mixing processes (dotted line) (Sv).

the terms in Eq. (A2) (Fig. 6). As discussed in section 3, a shallow and a deep overturning are found, with a net formation of MW and $\mathrm{AABW}$ at the expense of TW and LCDW. Note that in the validation exercise (IMMD08), because of a noisy estimate of the $b$ factor and of the binning process, the peak at 28.05 in Fig. 6 was found to be an overestimation of the actual value, computed from the direct transport evaluation, by $5-6$ Sv. The error derives from the estimate of the impact of lateral diffusion. Computing the same balance at $42^{\circ} \mathrm{S}$, and thus excluding the subtropical regions, the conversion of $\sim 11 \mathrm{~Sv}$ of mostly UCDW into MW is found to dominate the MW formation, but TW does not participate in the formation (not shown).

The dianeutral transport due to mixing, evaluated with Eq. (A2), is shown in Fig. 6. Mixing is found to make denser the water masses except for the densest waters in the coastal polynyas. In particular, mixing increases the transformation of TW into MW, but MW does not experience a significant transformation while flowing toward the tropics after the formation from airsea fluxes. Large positive-dianeutral fluxes (net production is $\sim 24 \mathrm{~Sv}$ ) are observed for the mixing of the IW/ UCDW waters. As a result, the large surface fluxes in the same density range are almost completely compensated by mixing (Fig. 6), in agreement with the scenario proposed by Sloyan and Rintoul (2001a). The peak at $\sim 28.1$ corresponds to a net conversion of $\sim 12 \mathrm{~Sv}$ of UCDW and LCDW into formation of denser LCDW and AABW ( $\sim 7-8 \mathrm{~Sv}$, if considering the error in the estimate discussed above). The mixing of a large 


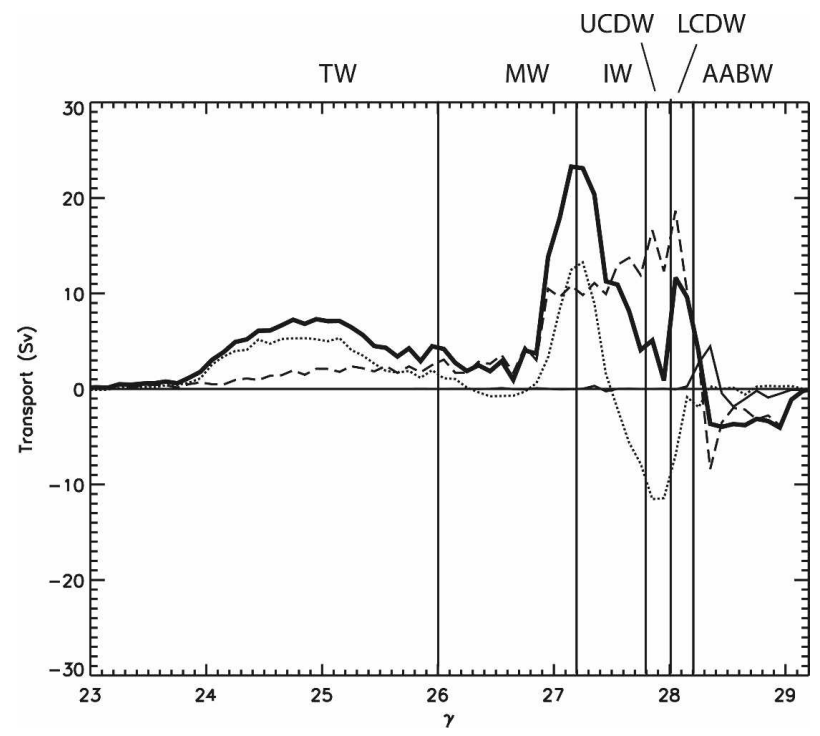

FIG. 7. Dianeutral fluxes due to mixing (Sv): total (thick solid line), lateral mixing (dashed line), vertical mixing (dotted line), and bottom boundary layer (thin solid line).

amount of UCDW/LCDW with extremely dense shelf water finally produces AABW (the deepest cell). The fate of CDW is thus mainly in the AABW, as pointed out also by Sloyan and Rintoul (2001b) and Talley et al. (2003).

Mixing in the model is due to profoundly different physical processes (vertical diffusion, lateral diffusion, and bottom boundary layer mixing) whose contributions to the dianeutral transports in the Southern Ocean vary with the water masses (Fig. 7). Vertical mixing dominates the consumption of TW. It also compensates the IW/UCDW destruction at the surface because it presents a distinct positive peak at $27.2(13 \mathrm{~Sv}$ of MW converges into IW) and a negative peak at 27.9 (11 Sv of CDW move into IW; note that it implies an upwelling of LCDW). Lateral diffusion, which sums up the lateral diffusion in the mixed layer (Marshall et al. 1999) and the mixing due to the nonlinearity of the equation of state (cabbeling and thermobaricity; McDougall 1987), makes denser the water masses and is significant only for the waters denser than the densest MW (about 10-15 Sv of MW, which are destroyed at 26.9). The model bottom boundary layer parameterization that mimics the dense gravity currents descending the slopes of Antarctica here produces $\sim 5 \mathrm{~Sv}$ of AABW through the conversion of denser shelf waters.

To gain insight into the dynamical balance of the THC in the Southern Ocean, two more questions need to be addressed: Where does the mixing occur? What are the roles of heat and freshwater in the transformations?

\section{c. The role of the mixed layer processes in the transformations}

To separate the transformations that are due to surface and subsurface processes from processes that are occurring at depth, we divided the domain into a "bowl," the maximum volume occupied by the mixed layer during the seasonal cycle, and an "interior," defined as the complementary domain (Marshall et al. 1999). The net export from the bowl to the interior is thus representative of the net subduction rate (Marshall et al. 1999). The transformations occurring in the bowl and in the interior are illustrated in Figs. 8a and 8c, respectively. As conjectured by Sloyan and Rintoul (2001b), the consumption of TW and the MW transformation into IW occur entirely in the bowl while the transformation of CDW into IW and AABW occurs in the interior, because of both vertical and lateral diffusive fluxes. Further, vertical mixing plays a different role in the bowl from that in the interior because the convergence in the surface fluxes at 27.2 is partially compensated by entrainment of dense waters into the bowl while the CDW buoyancy gain due to vertical mixing occurs essentially in the interior. In particular, the upwelling LCDW is transformed into IW before the outcrop into the bowl; that is, a small amount of LCDW is irreversibly transformed into lighter water even though it is not exposed to surface fluxes. This result is significant for the dynamics of the global thermohaline circulation, as we will discuss in more detail in section 5 . Here we note that apparently deep mixing can play a role in the upwelling of CDW as proposed by Tsujino and Suginohara (1999), for example.

To determine whether the mixing processes in the interior occur in the deep interior or at the interface between the bowl and the interior (Marshall et al. 1999), the same computations were repeated but with addition of an envelope of two grid points to the bowl volume. It is clear (Figs. 8b,d) that most of the mixing occurs within and in the proximity of the mixed layer (and therefore in the following we will use the latter as the definition of the bowl). Therefore, most of the mixing associated with the thermohaline circulation in the Southern Ocean is related to the air-sea and sea-ice interactions and to the nonlinearity of the equation of state (cabbeling and thermobaricity), whereas deep internal processes forced by external sources such as deep tidal mixing play a secondary role $(\sim 4 \mathrm{~Sv}$ of LCDW into UCDW).

When focusing on subpolar and polar regions $\left(42^{\circ} \mathrm{S}-\right.$ Antarctica; Fig. 9a) a net conversion of about $15 \mathrm{~Sv}$ of CDW into AAIW (6 Sv), MW (6 Sv), and TW (3 Sv) is found. Last, the net upwelling of UCDW almost coin- 

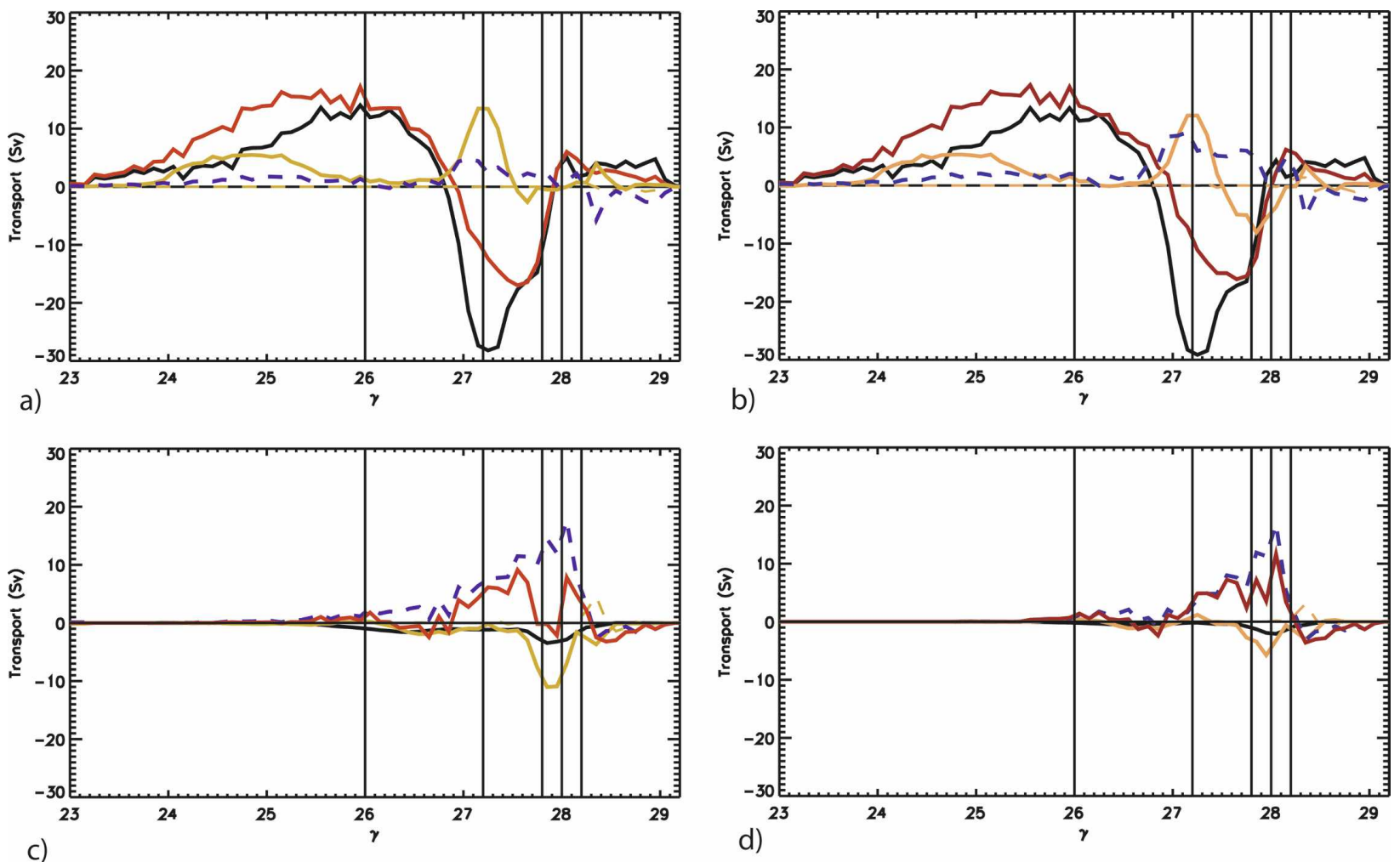

FIG. 8. Dianeutral fluxes (Sv) decomposed into bowl and interior. Line style corresponds to lateral mixing (dashed blue line), vertical mixing (yellow line), surface forcings (black line), and total net transformation (red line). (a), (b) Values for the bowl; (c), (d) values for the interior. (left) The bowl has been defined using a density criterium $(\Delta \rho=0.01)$. (right) The volume is defined by adding two grid points to the bowl.

cides with the surface water-mass formation, and thus mixing apparently does not play any role. In fact it occurs because the net conversion due to vertical diffusion is partially compensated by northward export of buoyancy through lateral diffusive fluxes (Fig. 9a).

The transformations occurring in the first $50 \mathrm{~m}$ of the polar and subpolar regions are also quantified, with the aim of separating the effect of the large northward Ekman transport [Fig. 9b; we use this definition of Ekman layer, a fixed-depth layer, for the sake of consistency with Sloyan and Rintoul (2001a)]. It is remarkable that the impact of surface buoyancy fluxes is here reduced because part of the shortwave radiation (not accounted for in previous studies, e.g., Marshall et al. 1999; Sloyan and Rintoul 2001b) heats the ocean below this layer. The net conversion of CDW into MW is nevertheless 2 times the net production rate (cf. with Fig. 9a). The Ekman dynamics, as expected, are thus promoting a large meridional transport of buoyancy-a buoyancy gain that in fact exceeds the net production in the bowl because most of the counteracting lateral and vertical mixing occurs between its bottom boundary and the bowl surface, especially in the thick mixed layer along the Subantarctic Front. In addition, the role of vertical mixing in promoting a net upwelling of CDW emerges clearly as the imbalance between vertical and lateral diffusion produces a net conversion of LCDW into lighter waters. The net conversion of $\mathrm{CDW}$ into AABW that characterizes the bowl (Fig. 9a) is thus the residual of a weak diffusive overturn into light waters, exported by the Ekman transport, and of a densification of CDW due to surface and lateral fluxes.

Last, the eddy or bolus overturning cell is thought to be superimposed on (and to compensate in part for) the Ekman circulation (or Deacon cell), which implies, in the upper layers, a partial compensation of the northward Ekman export, and the related buoyancy gain, and its opposite in the interior (e.g., Marshall and Radko 2003). In our simulation, the net eddy transport feeds the surface dianeutral transformation for more than $7 \mathrm{~Sv}$ (Fig. 10). In particular, in the bowl it opposes the Ekman transport ( $\sim 10 \mathrm{~Sv}$ of MW/IW into CDW). In the interior the opposite occurs for the intermediate waters. Of interest is that the eddy transport feeds, for $6 \mathrm{~Sv}$, the transformation of UCDW into LCDW. The latter observation agrees well with the UCDW south- 


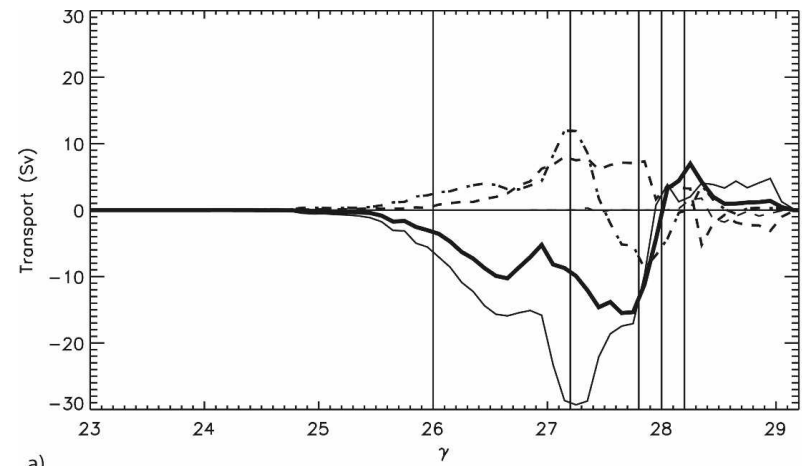

a)

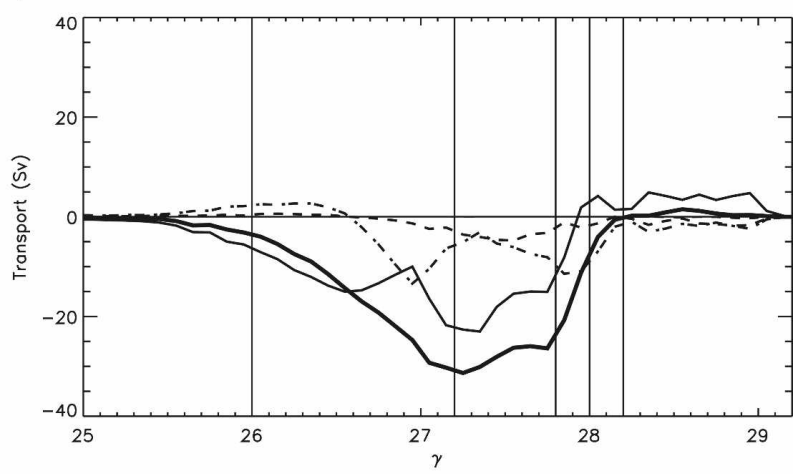

b)

FIG. 9. Dianeutral fluxes (Sv) in the bowl (a) for the region south of $42^{\circ} \mathrm{S}$ and (b) for the Ekman layer in the same region for lateral mixing (dashed line), vertical mixing (dotted-dashed line), surface forcings (thin solid line), and total net transformation (thick solid line).

ward transport due to eddies that, as proposed by Speer et al. (2000), feeds the deep overturning.

\section{d. The role of heat and freshwater in the transformations}

Watermass transformations due to heat and freshwater exchanges are presented in Figs. 11a,b (transformations occurring in the bowl poleward of $42^{\circ} \mathrm{S}$ ). Mixing of heat and mixing of freshwater contribute to the water-mass transformations in very different ways (Figs. 11a,b). To be more specific, the total heat component of transformations creates MW and AABW through the destruction of AAIW (Fig. 11a). Surface fluxes cool the IW and CDW while MW is made warmer (and lighter). Lateral heat diffusion is by far the most important mixing process affecting the heat redistribution, and it always corresponds to a net warming through a southward transport of heat. In particular, it contributes to the net warming of MW (Fig. 11a) and opposes the surface cooling at $\sim 27.6$. Vertical mixing plays a secondary role; of interest is that in the CDW class it has the opposite sign with respect to the total vertical mixing (Fig. 7); that is, the overturning of CDW into IW is

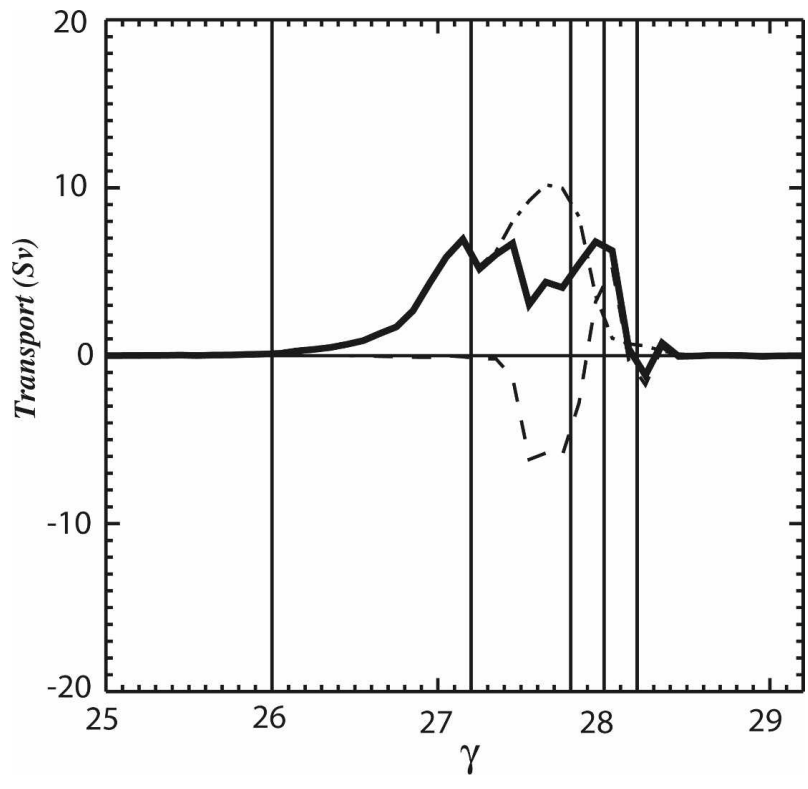

FIG. 10. Eddy bolus transport of buoyancy (Sv). The solid line is the total transport, the dotted-dashed line corresponds to the bowl, and the dashed line corresponds to the interior.

in fact associated with a net cooling. The same computation for the Ekman layer (Fig. 11c) shows that a large net transformation (more than $45 \mathrm{~Sv}$ centered at 27.1), fed mostly by the mean northward advection, implies the transformation of Antarctic Surface Water (AASW)/AAIW into SAMW. This large overturning is allowed mainly by the overwhelming of surface heat losses in the AAIW/UCDW range by lateral and vertical diffusion of heat and secondarily by surface heat fluxes in the MW class. Note that the Ekman meridional transport is small in the CDW range and that it is the vertical transport (Ekman pumping) that feeds the transformation of $\mathrm{CDW}$ into $\mathrm{AABW}$.

In the bowl in the subpolar and polar regions the dynamics of the freshwater contribution to the buoyancy budget creates AAIW from CDW (Fig. 11b) and has a smaller net impact on MW formation. The convergence is mainly due to the combination of surface fluxes, which generate SAMW and AAIW from CDW, and vertical mixing, which adds $15 \mathrm{~Sv}$ of $\mathrm{CDW}$ into AAIW but counterbalances the freshwater input into SAMW. Note that the total vertical mixing that promotes the upwelling of CDW (Fig. 11a) is in fact dominated by the freshwater redistribution (Fig. 11b). Last, an intense lateral diffusion of freshwater (at fronts) promotes a net transfer of about $20 \mathrm{~Sv}$ from SAMW to AAIW and from dense AAIW to CDW; it thus further reduces the impact of surface fluxes on SAMW freshening. Restricting the analysis to the Ekman layer makes it easier to understand (Fig. 11d) how the trans- 

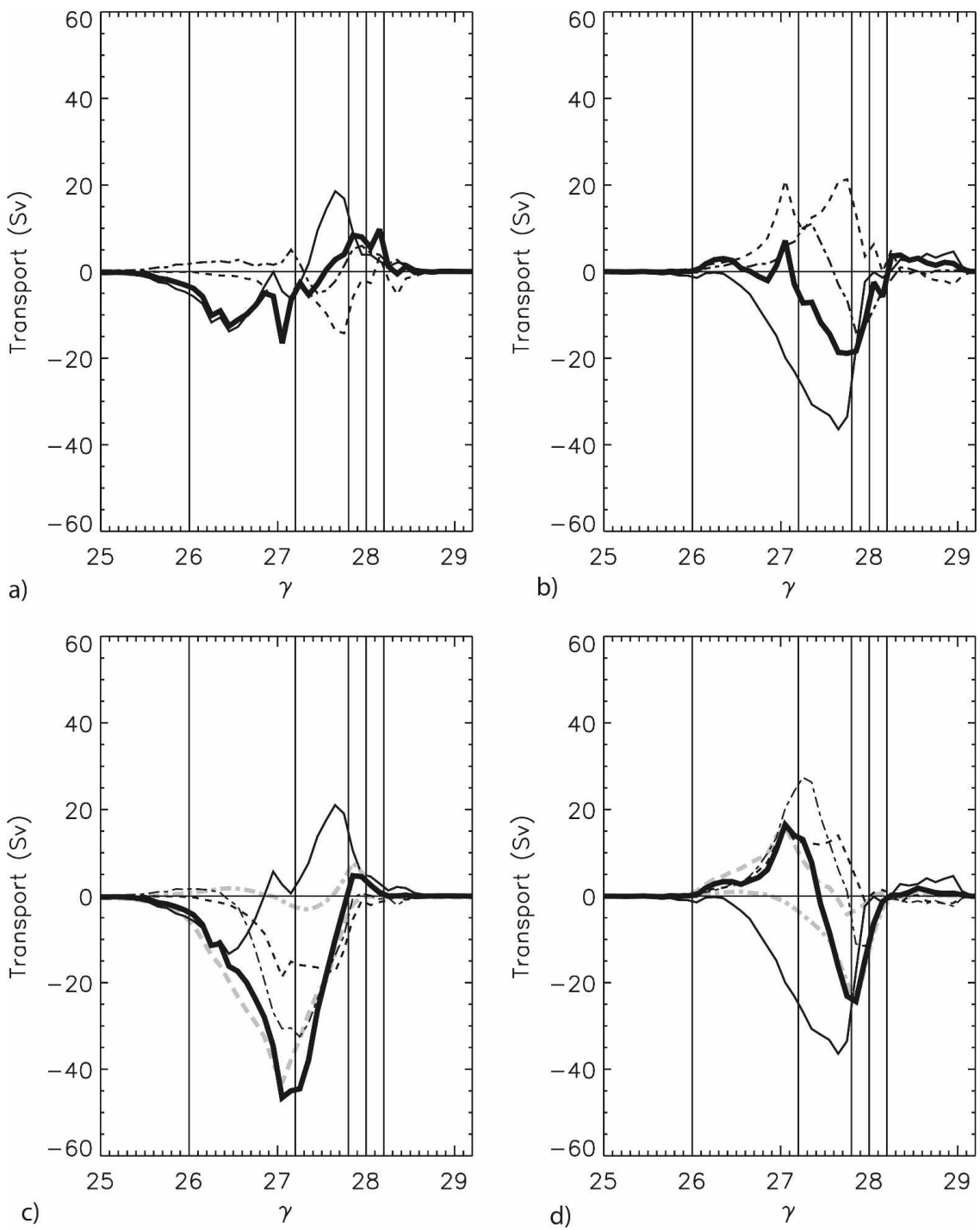

FIG. 11. (a) Heat budget for the bowl. (b) Freshwater budget in the bowl. (c) Heat budget in the Ekman layer. (d) Freshwater budget in the Ekman layer. Line styles correspond to total surface and dissipative fluxes (thick black line); vertical diffusion (dotted-dashed black line); vertical mean advection (dotted-dashed gray line); lateral diffusion (dashed black line); meridional mean advection (dashed gray line).

formation of CDWs into AAIW by mixing and surface fluxes is fed by the vertical advection (Ekman pumping) while the conversion of SAMW into AAIW is fed by the meridional Ekman transport.

The conversion of dense waters into MW described in the previous sections becomes more understandable when considering together the mechanisms of the heat and freshwater exchanges described above. To understand better the interplay between Ekman dynamics and mixing mechanisms, let us follow an ideal CDW water parcel that at the Antarctic Divergence is entrained in the bowl by the vertical mixing fed by the Ekman pumping. The parcel experiences four main transformations: 1) The parcel cools and, above all, freshens during the entrainment, thus entering into the AASW/IW class. Then, while part of it flows southward and is made denser by the combination of surface heat fluxes and mixing, most of the water will flow northward in the Ekman layer. 2) The latter water parcel experiences a transformation into lighter IW through further freshening due to surface fluxes that overcome the mixing with saltier waters and through warming because of the fact that the net surface cooling is more than compensated by mixing with warmer waters at the Polar Front and north of it. 3) At the Subantarctic Front further warming due to eddy diffusion overcomes 

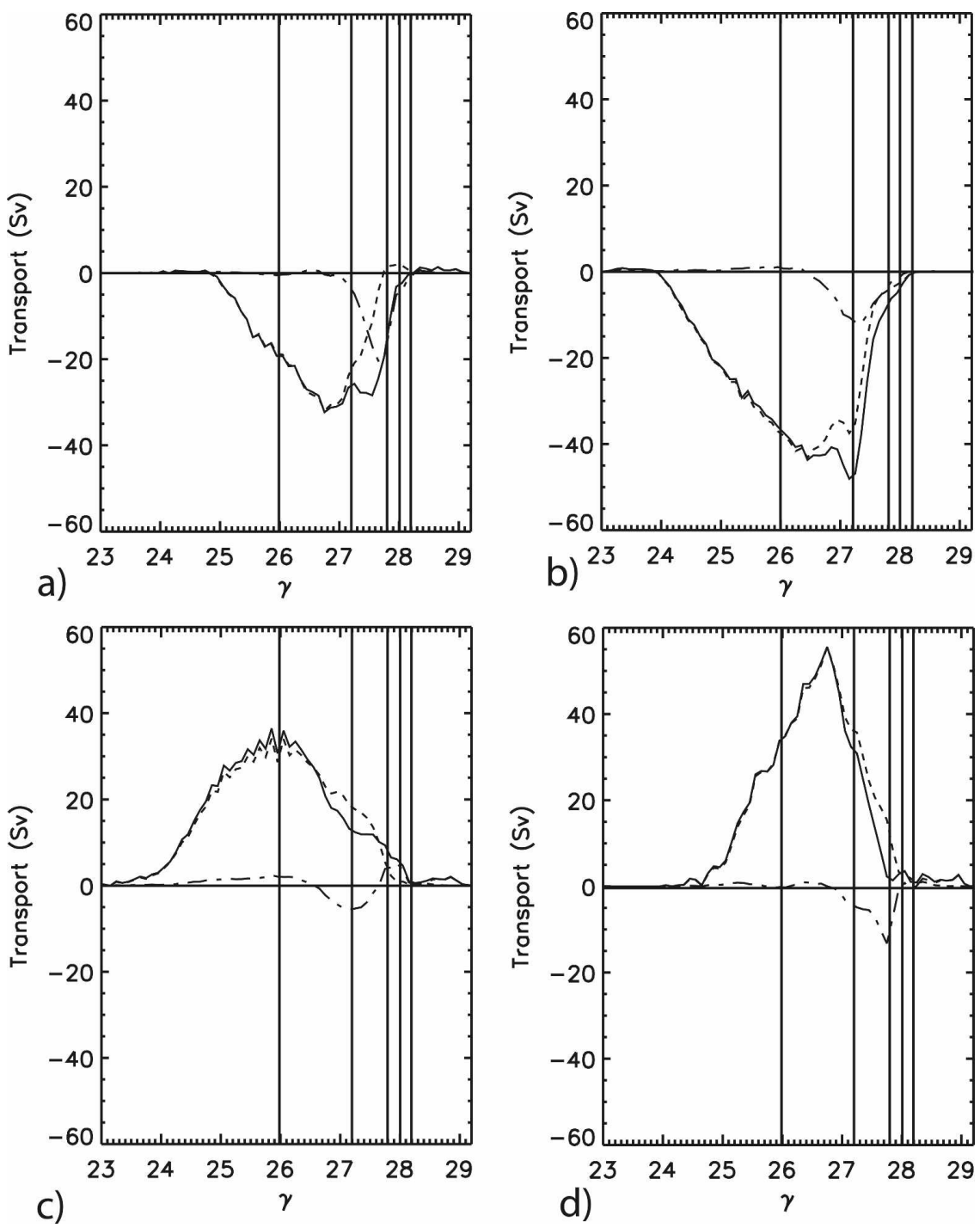

FIG. 12. The seasonal cycle of surface dianeutral fluxes for (a) austral spring (April-June), (b) austral summer (July-September), (c) austral autumn (October-December), and (d) austral winter (January-March). This choice of seasonal partitioning captures better the extrema of the seasonal cycle. The solid line is the total flux, the dotted line is the heat component, and the dotted-dashed line is the freshwater component.

the salt gain in the mixing with the much saltier and warmer TW and will then transform the parcel into dense MW. 4) Part of this dense MW will finally experience a net warming by surface fluxes that promotes the creation of the wide range of SAMW properties observed at $42^{\circ} \mathrm{S}$ (see also Rintoul and England 2002). Mixing with a large amount of subtropical water between $42^{\circ}$ and $30^{\circ} \mathrm{S}$ will further add heat and salt to the lightest MWs.

From the analysis above, surface IW (in fact AASW and not AAIW, which is in the same density class but is not necessarily the same water) is the effective collector of the surface freshwater excess and acts as an inter- mediary in the transformation of CDW into MW. Only a relatively small amount of AASW/IW contributes to the formation of the salinity minimum in the interior (through lateral diffusion). This result has been confirmed more quantitatively by a careful Lagrangian account of the salt gains and losses (D. Iudicone et al. 2007, unpublished manuscript) that showed that MW is the main conveyor of the surface freshwater excess.

To gain further insight into the dynamics of the transformation, the seasonal cycle is briefly analyzed. Deep mixed layers expose the densest water masses to the air-sea fluxes (i.e., ventilate the water masses) mainly during autumn and winter (Fig. 12) when the model 

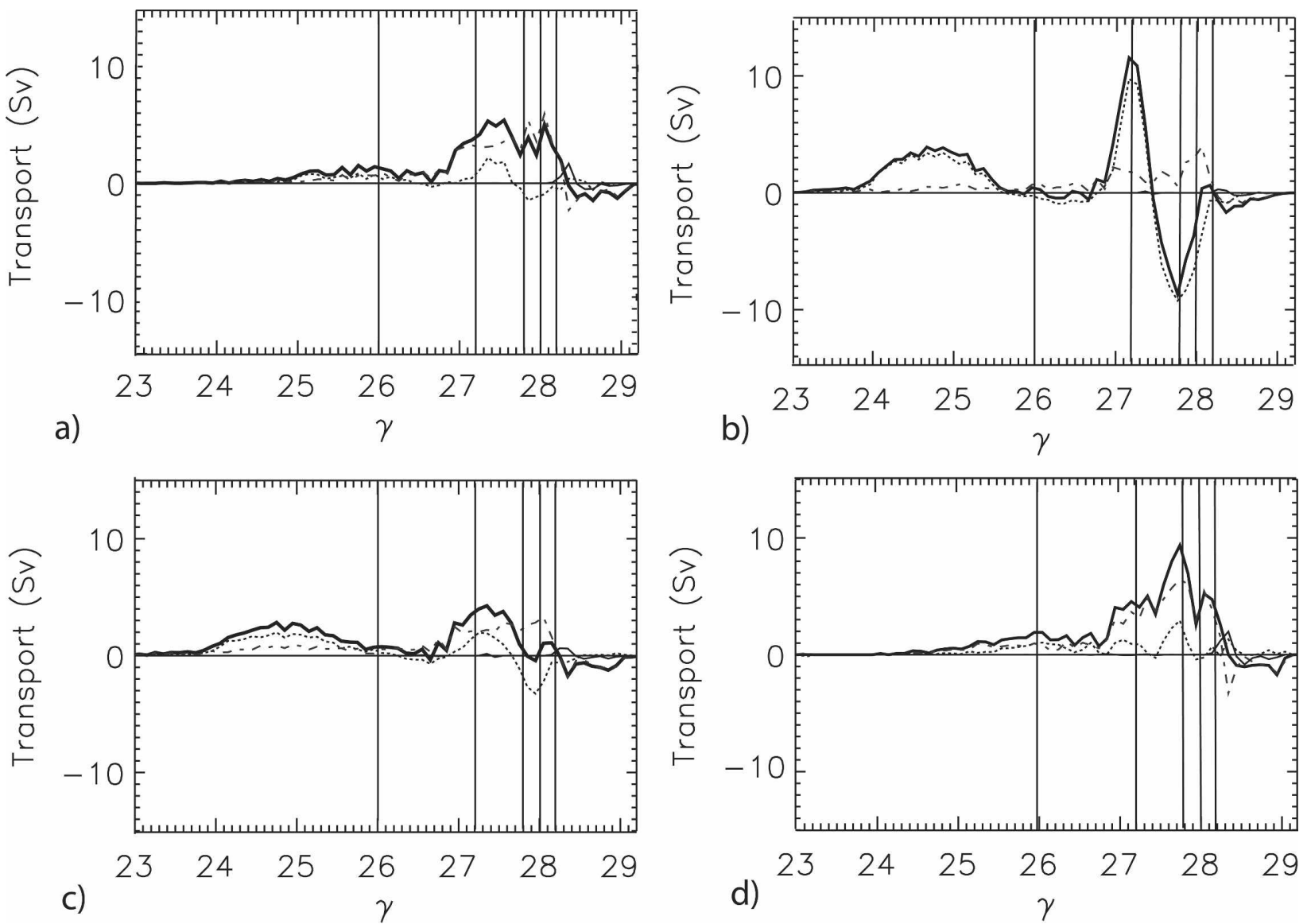

FIG. 13. As in Fig. 12, but for mixing. The solid line is the total flux, the dashed line is the lateral diffusive flux, and the dotted line is the vertical component.

heat loss is large almost everywhere. Note that at the highest densities the winter season is characterized by buoyancy losses that are less intense than in autumn because of the ice cover. Most of these losses are compensated by a buoyancy gain occurring in summer and spring, and, for instance, even if model LCDW partially upwells, LCDW does not present significant net transformations from air-sea interactions. Last, the freshwater input freshens CDW during autumn and winter, and AAIW is diluted during spring and summer.

The seasonal cycle of the diffusive fluxes (Fig. 13) presents two interesting features. The first is that lateral fluxes are stronger in winter and spring, that is, when the deepest mixed layers are usually observed. This result is consistent with Marshall et al. (1999), who found the same result for the North Atlantic. More important, the vertical mixing responsible for part of the CDW overturn and dominated by the freshwater component always makes MW and CDW converge into IW. Note that most of this conversion occurs in summer.

To explain this latter feature we present, first, the geographical distribution of the upwelling associated with the vertical mixing at the base of the bowl [Fig. 14; from Eq. (A6)]. It shows that most of the overturning occurs close to the Antarctic continent in the Indian and Pacific Ocean sectors of the Southern Ocean. The correspondence with the regions of maximum upward Ekman pumping is clear and expected (Fig. 15). Note that during summer the distribution of surface neutral densities (Fig. 16) shows that waters denser than 27.0 are found only south of $50^{\circ} \mathrm{S}$, that is, in the region of the upward Ekman pumping. Therefore most of the vertical mixing implied by the thermohaline circulation in the Southern Ocean is due to local conversion of salty and warm CDW into subsurface fresh and cold AASW/ IW during the Ekman upward motion. Because of the intense stratification, the vertical mixing due to wind forcing propagates downward the surface freshwater input that, in addition, is larger in spring and summer. The former CDW, now surface IW, is then conveyed northward by the Ekman transport. The upwelling mechanism thus is such that it does not require an out- 


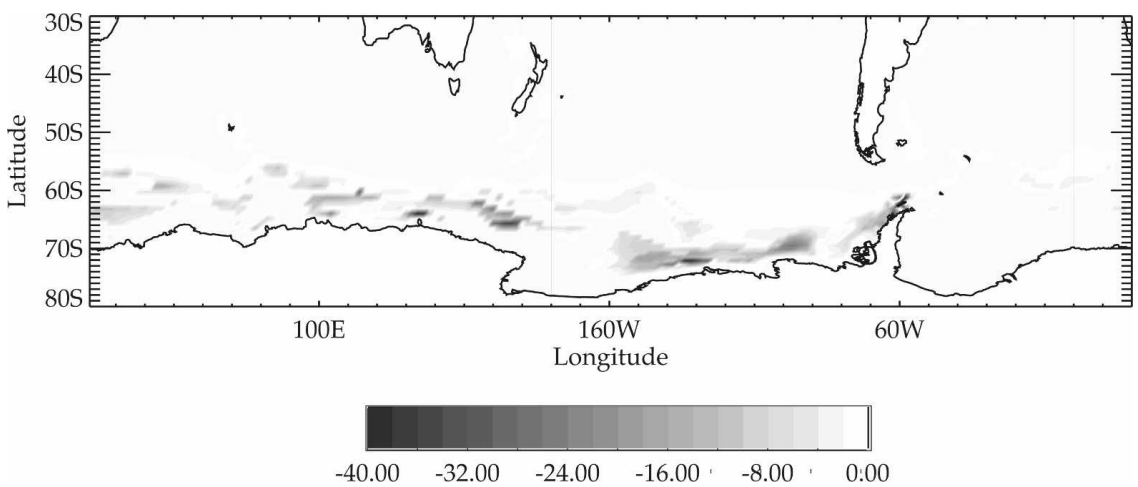

FIG. 14. Dianeutral velocity due to freshwater diffusion across the 27.8 isoneutral surface at the base of the bowl. The equivalent dianeutral velocity was obtained by dividing the dianeutral transport by the area of the grid box. Positive values are for fluxes toward larger densities.

crop of the deep waters and on the contrary is even more efficient in summer than in winter, that is, when the densest isoneutrals outcrop. In addition, the outcrop of the densest waters is partly below the ice cover and in regions of southward Ekman transport, that is, toward the regions of AABW formation. The upwelling mechanism also implies an efficient removal of the upwelled water before the subsequent cold season, a removal provided by the northward Ekman transport. The Lagrangian analysis of the NADW entrainment into the mixed layer in the same model nicely confirms the mechanism (Iudicone et al. 2008b).

\section{Discussion}

One of the main aims of this paper was to demonstrate that it is possible to have a fully consistent and quantitative account of the thermodynamics of the thermohaline circulation, and Fig. 17 depicts the account for the Southern Ocean. The consistency here is permitted by the use of a numerical model instead of experimental measurements. This makes the exercise interesting, though the figures proposed here should be considered to be only rough estimates of real values. In particular, we remind readers that, because of the low model resolution, eddies are parameterized (see discussion in section 4) and baroclinic currents are too broad, a drawback that in a forced ocean model can have a significant impact on the air-sea exchange estimates. Drawbacks are also the weak deep flows and the overestimation of the MW formation.

In summary, as shown in Fig. 17, the model CDW experiences intense transformations, involving several
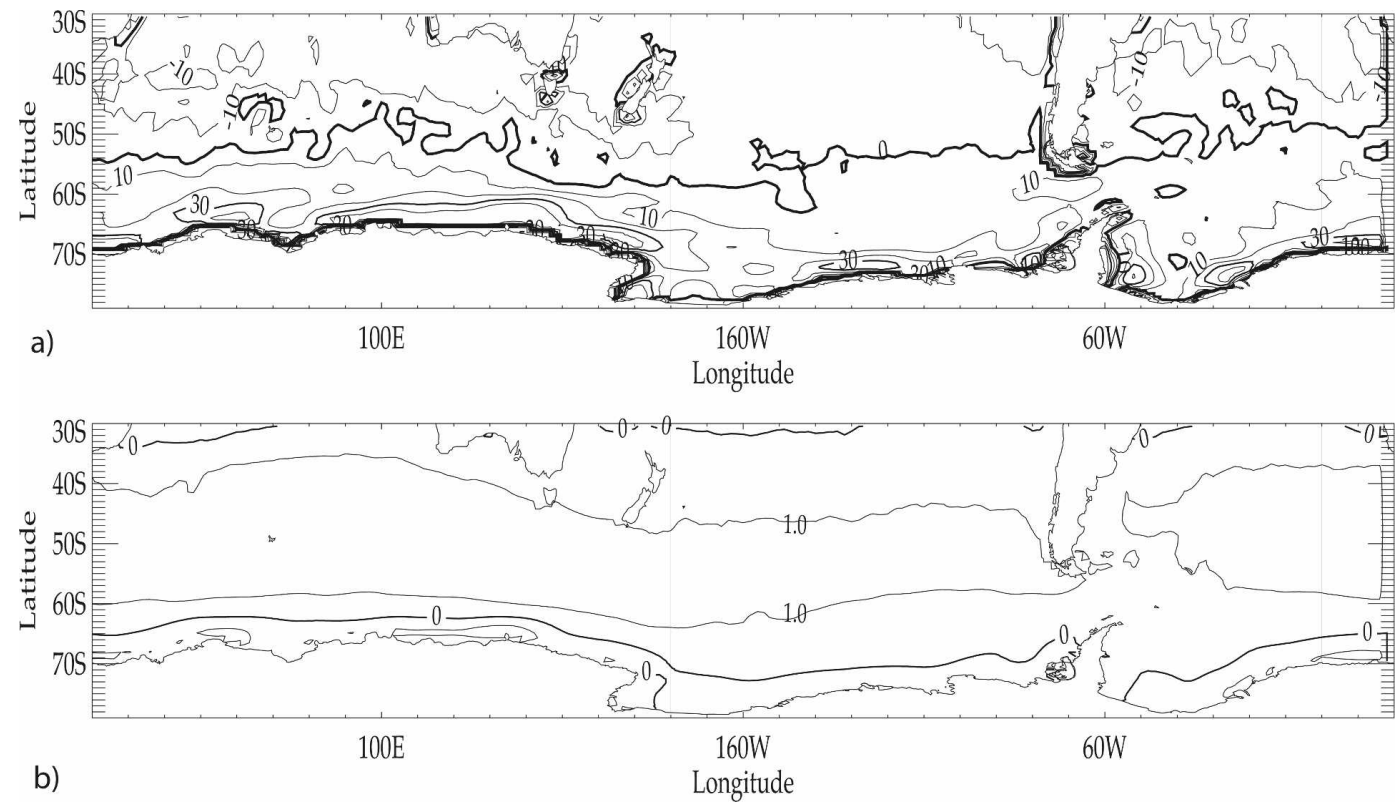

FIG. 15. Surface forcing fields: (a) Ekman pumping and (b) meridional Ekman transport. 


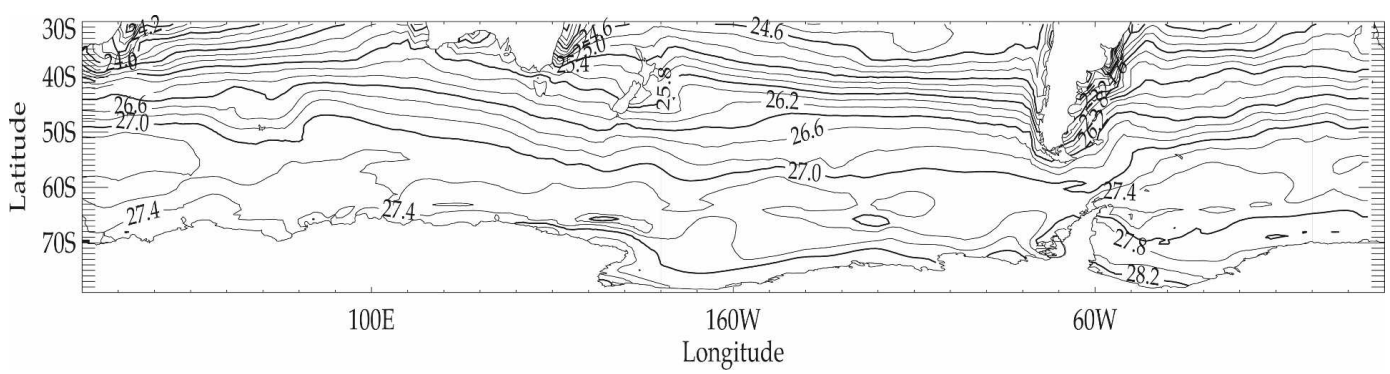

FIG. 16. Summer surface neutral density.

physical processes, and has basically two different fates. Part of the CDW gains buoyancy in the Antarctic Divergence from the downward diffusive propagation of the large freshwater excess at the surface. The resulting cold and fresh surface water (AASW), mostly in the IW class, is subsequently exposed to the surface fluxes (that freshen the water mass) and lateral diffusive fluxes (that warm the water mass) while moving northward within the Ekman layer. After a further warming due to surface fluxes it finally leaves the Southern Ocean as MW, whose formation comprises also the transformation of $12 \mathrm{~Sv}$ of warm and salty TW into MW through surface fluxes and mixing (the shallow overturning). Vertical and lateral diffusive processes in the bowl and in the interior reconvert part of the MW (14 Sv) into IW and IW into UCDW, and thus the large MW and IW formations by surface fluxes are in fact partially compensated. Part of the CDW is instead involved in the formation of AABW. Very dense shelf water, formed mostly by brine rejection $(5 \mathrm{~Sv})$ at the surface, mixes with LCDW, which is not exposed to surface fluxes, forming dense LCDW and AABW through lateral and (gravity currents) bottom boundary mixing.

The predominance of mixed layer processes in Southern Ocean transformations is consistent with the contemporary view of the ocean dynamics (e.g., Marshall et al. 1999). Nonetheless, what do we learn from this analysis about the relationship among water-mass formation through surface buoyancy fluxes, mixing processes, and subduction rates in the Southern Ocean? The subduction rate is a purely kinematic concept, defined as the velocity of a fluid parcel relative to the base of the mixed layer (e.g., Woods 1985), in general related to Sverdup and Ekman dynamics. The opposite movement of water into the mixed layer is defined as obduction. The subduction rate per water mass is thus a measure of the total transport from the mixed layer into the interior, which at annual scale is partially compensated by a transport into the mixed layer (obduction). Thus the net annual formation rates in the bowl, estimated with the thermodynamic budget, must be compared with the annual subduction rate minus the annual obduction rate per water mass (Marshall et al. 1999); that is, surface dianeutral fluxes + diffusive dianeutral fluxes $=$ subduction - obduction. It is thus perfectly admissible to have huge subduction rates even if net water-mass formations (left-hand side above) sum to zero, for instance.

Our analysis allows us to make two interesting remarks on this issue. First, especially at high latitudes, water-mass formation due to surface buoyancy fluxes possibly overestimates the net formation rate, because of compensation by mixing processes (section 4; see also Marshall et al. 1999). In the simulated Southern Ocean, the formation of water masses due to surface fluxes largely exceeds the net basin production, which is a scenario already proposed by some authors (e.g., Speer et al. 2000; Sloyan and Rintoul 2001a,b). In particular, the large internal transformations of IW into CDW that partly compensate the surface fluxes are coherent with estimates from inverse modeling given by Sloyan and Rintoul (2001a,b). Note that, unlike in Speer et al. (2000), we found also a significant net conversion of TW into MW (the shallow overturning; see also Talley et al. 2003) that has important implications on, for example, the MW and IW freshwater export efficiencies.

Second, Iudicone et al. (2008b) showed with a quantitative Lagrangian tool that $\sim 76 \mathrm{~Sv}$ of the northward flow in the thermocline at $30^{\circ} \mathrm{S}$ subducted from the Southern Ocean mixed layer (the ventilation of bottom layers is $\sim 4-5 \mathrm{~Sv}$ ) - a value that is almost 2 times the net formation rate due to surface buoyancy fluxes ( $\sim 30-40 \mathrm{~Sv}$; MW + IW) and thus is even larger than the net formation rate $(\sim 20 \mathrm{~Sv}$; MW + IW). This implies, from the equality above, that obduction is significant in the region $(\sim 30-50 \mathrm{~Sv})$, which is a perfectly plausible result given the huge recirculation in the subtropical gyres plus the upward Ekman pumping into the mixed layer in the Antarctic Divergence. Of interest is that, using the usual kinematic method applied to in situ data and surface-forcing climatological 


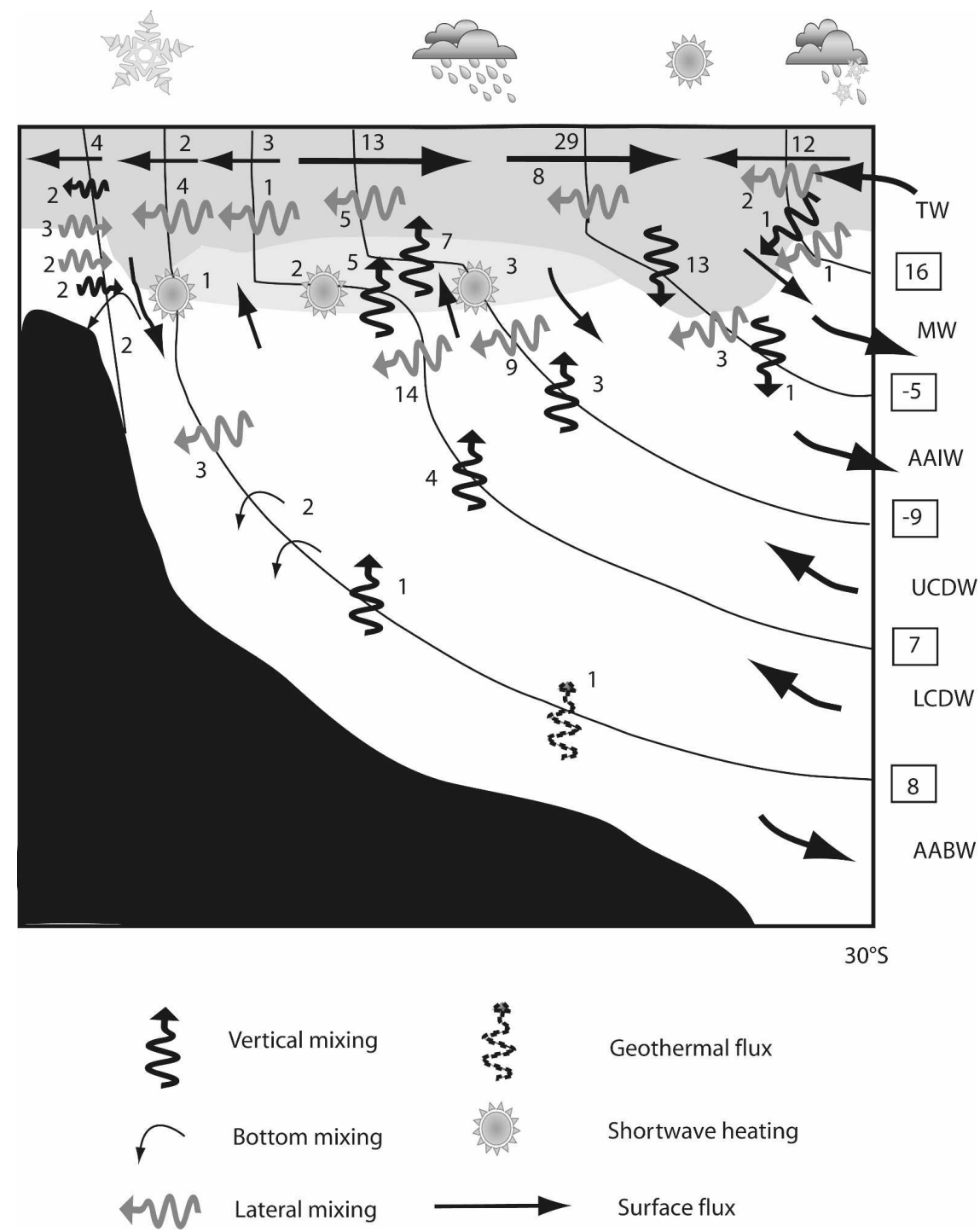

FIG. 17. Sketch of the principal water-mass transformations (Sv). Numbers on the right refer to the net dianeutral transport (positive values correspond to transport toward larger densities). Numbers are rounded off, and thus the net budgets are within $1 \mathrm{~Sv}$ of the sum of the components. The dark-shaded region is the bowl, and the light-shaded region is the stratified region impacted by the solar heating. Note that although globally the net transformation is in agreement with Table 2 the partitioning of the net consumption CDW into UCDW and LCDW is different here. This is due to the binning in density associated with Eq. (A2) that produces an overestimate of the lateral mixing between UCDW and LCDW in the interior (i.e., the 14-Sv value is about double that of the real figure; see discussion in section 4 and in the appendix).

datasets, Karstensen and Quadfasel (2002) found an annual kinematic subduction poleward of $30^{\circ} \mathrm{S}$ of $\sim 65$ $\mathrm{Sv}$, which is in agreement with our estimate above. They found also a very similar value for the air-sea formation rates and used this latter estimate as further evidence of intense ventilation of water masses in the Southern Ocean. From the discussion above it is obvious that a direct comparison is not really meaningful because 1) ventilation (subduction) and formation rates are not directly related and 2), in the case of the Southern Ocean, obduction and mixing processes are not negligible.

The surface fluxes are here in part compensated by lateral fluxes in the interior. Two possible main mechanisms can explain it: the effects of the nonlinear equation of state (cabbeling and thermobaricity) and the 
dianeutral diffusion due to the slope limitation in the isoneutral diffusion. For the latter issue, the maps of dianeutral transports due to lateral mixing projected on isoneutral surfaces are indeed noisy, especially for densities larger than 27.8, indicating the presence of numerical diffusive effects. Nevertheless, cabbeling is definitely a possible cause for the lateral diffusion dianeutral transport for intermediate densities (here $\sim 5$ $10 \mathrm{~Sv}$ ); that is, it can be a main source for feeding the AAIW and UCDW layers. In the Lagrangian analysis of the origins of the Pacific AAIW, Iudicone et al. (2007) found that most of the modeled recently formed AAIW was in fact SAMW that becomes denser while flowing along the Subantarctic Front in the interior. Maxima for this dianeutral transport are observed at the Subantarctic Front, especially in the Indian Ocean sector, and in the western boundary currents (not shown). Note that, summing up the estimates from in situ data in You $(1998,2002)$ and You et al. (1995), about $10-15 \mathrm{~Sv}$ of IW are transformed into denser water by cabbeling and thermobaricity along the Subantarctic Front. Marsh (2000) estimated the sole effect of cabbeling in a global isopycnal model and interestingly found a net transport of $\sim 7 \mathrm{~Sv}$ across $27.2 \mathrm{~Sv}$ that is in agreement with our estimate. At larger densities (and lower temperatures), for which thermobaricity should be more important, we note only that, even if the fields are very noisy, regions of coherent intense transformations exist around Antarctica and at depth in the Atlantic sector of the Southern Ocean. A more detailed analysis using an eddy-resolving GCM is needed to definitively address the issue.

We have found also that lateral diffusion in the bowl, related to eddy dynamics, plays an important role, especially during winter. In fact, in the bowl, isoneutral surfaces are close to the vertical and the eddy diffusivity should be regarded as a net physical buoyancy source. Marshall's group (e.g., Marshall and Radko 2003; Marshall et al. 2006) has proposed a $2 \mathrm{D}$ conceptual model of the Southern Ocean in which the meridional circulation is in fact the residual between the Ekman transport, surface buoyancy fluxes, and the eddy-driven buoyancy fluxes (or lateral diffusion), the latter being associated with the stratification strength (see also Bryden and Cunningham 2003). Here we have found that eddy dynamics contribute through 1) a bolus transport $(\sim 10 \mathrm{~Sv})$ that in fact compensates in part the Ekman circulation (Deacon cell) and 2) the fact that lateral diffusion in the mixed layer is significant $(\sim 10 \mathrm{~Sv})$. These important eddy-driven effects are indeed in broad agreement with the Marshall and Radko (2003) scenario. Their scenario and ours differ in some important details, however. Marshall and Radko (2003) pre- dict from their analysis that the convergence in the residual meridional circulation at the surface produces the injection into the interior of about $10 \mathrm{~Sv}$ of AAIW. We noted that lateral mixing (especially cabbeling, not included in their analysis) is so important that it partially compensates the AAIW formation. [Here we found $6 \mathrm{~Sv}$ of AAIW formed at $42^{\circ} \mathrm{S}$ and 3-4 Sv formed at $30^{\circ} \mathrm{S}$; a large formation of AAIW is not observed in either the data (e.g., Sloyan and Rintoul 2000; Talley et al. 2003) or the OGCMs (e.g., Hirst and McDougall 1998)]. From the discussion above (see also Fig. 13) we thus propose that Marshall and Radko's (2003) AAIW formation mechanism is possibly more suitable to describe the SAMW formation. [Of interest is that a closer look at salinity and oxygen distributions projected on residual streamfunctions in Karsten and Marshall (2002, their Figs. 7 and 8 ) suggests that at $43.3^{\circ} \mathrm{S}$ high-oxygen waters are much shallower than the AAIW salinity-minimum waters; that is, SAMW is more closely connected to the mixed layer dynamics.]

The need to constrain the dynamics of the overturning in the Southern Ocean has recently become more critical because of its possible impact on climate variability through the modulation of the overturning of NADW into lighter waters, a key element of the thermohaline circulation. The Southern Ocean and the NADW circulations are in fact coupled on millennial scales (e.g., Knutti et al. 2004). Further, Southern Ocean wind variability could have a direct influence on the NADW production rate on shorter time scales through Ekman dynamics (e.g., Toggweiler and Samuels 1993). The latter issue is very controversial because the role in the dynamics of the global thermohaline circulation of the overturning of NADW into lighter waters in the Southern Ocean is not clear (Rahmstorf and England 1997; Goodman 1998; Toggweiler and Samuels 1998; Wunsch and Ferrari 2004; Klinger et al. 2003; 2004) and the existence of this overturning is not unanimously acknowledged (e.g., Sloyan and Rintoul 2001a; Wunsch and Ferrari 2004). Klinger et al. (2004) conclude that to date there is no theory that can even approximately predict the large-scale overturning due to the winds in a simple closed basin and that analysis of the role of surface Ekman transports and subsurface diffusivity in the transformations of NADW into lighter water in more realistic cases is necessary.

For the existence of a net NADW overturning (upwelling), the observed outcrop of NADW in remote polar regions is used as evidence against the Toggweiler and Samuels (1993) scenario (Sloyan and Rintoul 2001a; Wunsch and Ferrari 2004). The occurrence in our model of a net transformation in the interior of CDW into IW/AASW relaxes the inconsistency be- 
tween the occurrence of a net NADW overturning (upwelling) and the secondary role of surface fluxes at the outcrop. Further, we can speculate that, given a fixed freshwater surface flux, stronger southern winds can amplify the upwelling and thus the conversion of NADW into subsurface waters in the Southern Ocean in the model. However, it is difficult to establish how the process is significant, remembering that the overturn into lighter water explains only less than $40 \%$ of NADW transformations; a similar amount of LCDW becomes AABW, and the model misses the observed NADW deep flows into the Indian Ocean basin.

To be more specific about the NADW overturning mechanism, we recall that the inviscid upwelling mechanism of Toggweiler and Samuels (1993) needs a thermodynamic foundation to be fully consistent with the water-mass transformations implied by definition by an overturning. The idealized model studies by Tsujino and Suginohara (1999) and Klinger et al. (2004) recently outlined a "wind-enhanced thermohaline circulation" scenario, in which an unspecified diffusive vertical propagation of heat in the Southern Ocean is the overturning source mechanism. In this regard, we have shown that the first conversion of LCDW/NADW into lighter water is not related to a heat gain (not obvious in polar regions) but to the downward propagation of the surface freshwater excess through vertical mixing that compensates the upward Ekman pumping through the base of the mixed layer. In the process the vertical mixing actually cools these waters. The heat gain occurs later in the Ekman layer and is due to vertical and (eddy driven) lateral diffusion, whereas a direct surface heat gain occurs only after the overturning into mode waters is accomplished.

Last, we have shown that this mixing activity is clearly related to the mixed layer dynamics (background vertical diffusivity at $200 \mathrm{~m}$ is about $10^{-5} \mathrm{~m}^{2}$ $\mathrm{s}^{-1}$ ) and thus its energetic source is to be sought in the surface forcings (Webb and Suginohara 2001) more than in externally forced deep mixing.

\section{Conclusions}

We have presented a quantitative analysis of the thermodynamic processes involved in the functioning of the thermohaline circulation in the Southern Ocean in a steady-state simulation of a coupled ice-ocean model. This occurred because during the study a specific new diagnostic approach was developed (IMMD08) that allowed us to include the effect of the penetrative solar radiation, to compare deep and surface dianeutral transports, and to investigate the dynamics of transformation in a unique framework.
First, the model simulation was validated against known volume transports at $30^{\circ} \mathrm{S}$ where computed and partitioned into neutral density classes. When compared with the results of inversion of in situ data, the overall pattern is found to be in relatively good agreement, with some important drawbacks such as the weak deep overturning of LCDW/NADW into AABW.

Surface fluxes in the model Southern Ocean have been found to produce almost $40 \mathrm{~Sv}$ of Subantarctic Mode Water. Note that in the model the heat fluxes are slightly negative (cooling) in polar regions; nevertheless they do not compensate the large amount of freshwater input. The ice-ocean interactions (brine rejection) form $5 \mathrm{~Sv}$ on the shelves of Antarctica and in the Weddell Sea. Mixing transforms one-half of the SAMW into intermediate water and Upper Circumpolar Water; however, although it compensates the transformation of AAIW/AASW into SAMW at the surface, this is not the case for UCDW. Lower Circumpolar Water mixes in the interior with the shelf water. The present study therefore is in agreement with the shallow and deep overturning recently proposed. Above all, this study quantifies the role of surface fluxes and mixing as well as confirms the large transformations occurring in the AAIW class-transformations that essentially compensate each other and finally produce only a small net export toward the tropics.

We have found evidence of LCDW (NADW) upwelling in the Southern Ocean in the model-upwelling that is associated with subsurface dynamics. For the buoyancy gain in the NADW upwelling suggested by Tsujino and Suginohara (1999), the "wind-enhanced thermohaline circulation," here we demonstrate that the buoyancy gain is mainly at the base of the mixed layer, where upward Ekman transport pushes the water against the large salinity gradients, and that a major role is played by the downward propagation of the surface freshwater excess rather than by a heat gain. The role of solar radiation in warming the subsurface layers is also significant. The analysis presented here refers to integral quantities for the whole Southern Ocean. These results are complemented in a companion paper (Iudicone et al. 2008b) in which the use of a quantitative Lagrangian diagnostic tool (Blanke and Raynaud 1997) allows identification of water-mass pathways associated with the transformations here quantified, clarifying the connections between the subduction processes and the three-dimensional ocean circulation.

Last we note that although we use a $K_{z}$ that is at the highest end of the range of observed deep values (Wunsch and Ferrari 2004), our deep dianeutral transports are still definitely smaller than in data inversions. We attribute this deficiency to the insufficient dense 
shelf water formation (surface AABW formation is most likely underestimated) and to the failure of present approaches in parameterizing the mechanisms of vertical mixing in the interior (e.g., Wunsch and Ferrari 2004; Simmons et al. 2004). Model improvements as well as more observations are needed to fix the issue. Last, the relatively low spatial resolution of the GCM used here allows for a tentative description of the physics of the thermohaline circulation that in perspective needs corroboration with the analysis of models with higher spatial resolution.

Acknowledgments. The authors thank Prof. Lynne Talley and the two anonymous reviewers for their most constructive and knowledgeable comments. We acknowledge J. Jackett and T. McDougall for their software for the neutral density computation. This research is supported by the French Programe National d'Etude du Climat (PNEDC) (Project BILBO). A contribution from the Italian PNRA (Project CANOPO) is also acknowledged.

\section{APPENDIX}

\section{A Generalized Approach to the Diagnosis of Watermass Transformations}

We report here a summary of the theoretical results presented in IMMD08, who generalized the classical approach to the quantification of water-mass transfor- mations due to mixing processes and surface buoyancy fluxes. Two main aspects make this approach novel and appealing with respect to previous methods [reviewed in Large and Nurser (2001)]: 1), because it uses neutral densities, the formulation is valid for the entire water column, and 2) the whole ensemble of oceanic processes that are responsible for the water-mass transformations is considered-in particular, the penetrative character of solar irradiance.

The evolution equation for neutral density in terms of nonadvective processes $d$ and external forcing $f$ is

$$
\frac{D \gamma}{D t}=\frac{\partial \gamma}{\partial t}+\mathbf{U} \cdot \nabla \gamma=\gamma b\left(d_{\rho}+f_{\rho}\right)=\gamma\left(d_{\gamma}+f_{\gamma}\right) .
$$

The factor $b$ is a nontrivial function of space because it depends on the thermodynamic properties of seawater and the geographical water-mass distribution, and it can be different from unity.

Consider a limited area of the ocean with an open boundary. We denote $S_{\gamma}$ as the surface with neutral density $\gamma$ over the limited domain, $V_{\gamma}$ is the volume sandwiched between two surfaces $S_{\gamma}$ (the ocean bottom $H$ and the ocean surface $\mathrm{OS}_{\gamma}$ ), the open boundary is $\psi_{\gamma}$, $E_{\gamma}$ is the volume flux of fluid entering/exiting the domain $V_{\gamma}$ across the open boundary and surface, respectively, and $\Omega_{\gamma}$ is the total volume flux across the $S_{\gamma}$ (i.e., the dianeutral volume flux). The sign convention is that all the fluxes are positive if entering $V_{\gamma}$.

The total volume flux $\Omega_{\gamma}$ across $S_{\gamma}$ is

$$
\Omega_{\gamma}=\frac{\partial}{\partial \gamma} \iint_{V_{\gamma}} \int_{\rho} \rho b\left(d_{\rho}+f_{\rho}\right) d v=\frac{\partial}{\partial \gamma} \underbrace{\iint_{V_{\gamma}} \int_{D} \rho b d_{\rho} d v}_{D}+\frac{\partial}{\partial \gamma} \underbrace{\iint_{V_{\gamma}} \int_{D^{\prime}} \rho b f_{\rho} d v}_{F},
$$

or, to be more concise,

$$
\Omega_{\gamma}=\frac{\partial D}{\partial \gamma}+\frac{\partial F}{\partial \gamma}
$$

where $D$ and $F$ are the volume-integrated effects of mixing and forcing over $V_{\gamma}$. Here, $\Omega_{\gamma}$ is usually referred to as the water-mass transformation from water masses lighter than $\gamma$ into water masses denser than $\gamma$, and $M_{\gamma}$ $=-\partial \Omega_{\gamma} / \partial \gamma$, the convergence of $\Omega_{\gamma}$, refers to the watermass formation at a given density $\gamma$ (Walin 1982; Speer and Tziperman 1992). Therefore, $\partial D / \partial \gamma$ and $\partial F / \partial \gamma$ are the transformations driven by ocean physics and external forcing, respectively. Equation (A2) expresses the fact that a cross-dianeutral volume flux (transformation) directed from light to dense, $\Omega_{\gamma}>0$, requires a density supply either by ocean physics or by the forcing.
Up to now we have assumed neither incompressibility nor stationarity. Assuming incompressibility, and considering the volume budget of $V_{\gamma}$, we have the equation for the water-mass evolution in a neutral density framework:

$$
\frac{\partial V_{\gamma}}{\partial t}-\Psi_{\gamma}-E_{\gamma}=\Omega_{\gamma}
$$

The forcing term $\partial F / \partial \gamma$ in Eq. (A2) can be derived from

$$
\begin{aligned}
F= & \iint_{\mathrm{OS}_{\gamma}}-b \alpha \frac{Q-I_{0}}{C_{p}} d s+\iint_{\mathrm{OS}_{\gamma}} b \rho e\left[-\alpha\left(T_{e}-\mathrm{SST}\right)+\beta S\right] d s \\
& +\iint_{z=-H}-b \alpha \frac{G}{C_{p}} d s+\iiint_{V_{\gamma}}-b \alpha \frac{1}{C_{p}} \nabla \cdot I d v, \quad \text { (A5) }
\end{aligned}
$$


where $Q$ is the net heat flux across the sea surface, $I_{0}$ is the total surface solar radiation (i.e., the portion of the surface heat flux that penetrates inside the ocean), $I=I(\mathbf{x})$ is the solar irradiance flux that reaches the interior, SST is the sea surface temperature, $e$ is the net surface freshwater flux (evaporation minus precipitation and river runoffs), $T_{e}$ is the temperature of the surface freshwater budget (i.e., the temperature of the different freshwater sources), $G$ is the geothermal heat flux across the ocean sea floor $(z=-H)$, and $\delta$ is the Dirac operator (homogeneous to the inverse of a length).

The key point here is that the forcing term does not reduce to a surface integral as in the classical theory (e.g., Speer and Tzipermann 1992); the last term in Eq. (A5), being associated with the penetrative solar irradiance $I$, was previously omitted where all the heat exchanged with the atmosphere is supposed to be captured at the surface.

The term $\partial D / \partial \gamma$ includes all the effects of ocean physics on the transformations. In fact, $d_{\gamma}$ can be written as

$$
d_{\gamma} \equiv \boldsymbol{\nabla} \cdot(k \boldsymbol{\nabla} \gamma)+F S_{\gamma}=\boldsymbol{\nabla} \cdot\left(k_{I} \nabla_{I} \gamma\right)+\nabla\left(k_{\perp} \nabla_{\perp} \gamma\right)+F S_{\gamma}
$$

that is, the tendency due to mixing processes can be expressed here in terms of the divergence of isoneutral and dianeutral fluxes (subscript $I$ and $\perp$, respectively) plus mixing due to the bottom boundary parameterization (i.e., dense overflows) and sources and sinks due to double diffusive processes such as salt fingering and diffusive convection (last term on the right-hand side). The first term on the right-hand side, in particular, includes the thermobaricity and cabbeling transport through $S_{\gamma}$ (McDougall 1987).

In practice we evaluate the irreversible production of "density" in the above equations by examining the corresponding production terms of potential temperature and salinity through the locally referenced expansion/ contraction coefficients. The implementation of Eq. (A2) is thus straightforward, with the exception of the $b$ factor that has no state equation and has to be estimated empirically. After several tests, an annual mean $b$ field was derived by taking the local average of the horizontal ratio $\Delta \gamma / \Delta \rho$ in every grid point. This avoided problems in the mixed layer. To validate the application of the new formulation to the ocean model, IMMD08 computed the budget of transformations for the Southern Ocean. The main discrepancies occur at about 27.3-27.6 and at 28.0 and are due to the binning on finite-size bins and to noise in the estimate of the $b$ factor.

\section{REFERENCES}

Beckmann, A., and R. Döscher, 1997: A method for improved representation of dense water spreading over topography in geopotential-coordinate models. J. Phys. Oceanogr., 27, 581591.

Blanke, B., and P. Delecluse, 1993: Variability of the tropical Atlantic Ocean simulated by a general circulation model with two different mixed-layer physics. J. Phys. Oceanogr., 23, $1363-1388$.

_ and S. Raynaud, 1997: Kinematics of the Pacific Equatorial Undercurrent: An Eulerian and Lagrangian approach from GCM results. J. Phys. Oceanogr., 27, 1038-1053.

— nostic of interior ocean ventilation. Geophys. Res. Lett., 29, 1267, doi:10.1029/2001GL013727.

Broecker, W. S., 1987: The biggest chill. Nat. Hist., 96, 74-82.

Bryden, H. L., and S. A. Cunningham, 2003: How wind-forcing and air-sea heat exchange determine the meridional temperature gradient and stratification for the Antarctic Circumpolar Current. J. Geophys. Res., 108, 3275, doi:10.1029/ 2001JC001296.

Conkright, M., S. Levitus, T. O'Brien, T. Boyer, J. Antonov, and C. Stephens, 1998: World Ocean Atlas 1998 CD-ROM Data Set Documentation. NODC Internal Tech. Rep. 15, 16 pp.

Cunningham, S. A., S. G. Alderson, B. A. King, and M. A. Brandon, 2003: Transport and variability of the Antarctic Circumpolar Current in Drake Passage. J. Geophys. Res., 108, 8084, doi:10.1029/2001JC001147.

da Silva, A. M., C. C. Young, and S. Levitus, 1994a: Anomalies of Heat and Momentum Fluxes. Vol. 3, Atlas of Surface Marine Data 1994, NOAA Atlas NESDIS 8, 411 pp.

$\longrightarrow,-$, and 1994b: Anomalies of Freshwater Fluxes. Vol. 4, Atlas of Surface Marine Data 1994, NOAA Atlas NESDIS 9, $308 \mathrm{pp}$.

Delecluse, P., and G. Madec, 1999: Ocean modeling and the role of the ocean in the climate system. Modeling the Earth's Climate and Its Variability, W. R. Holland, S. Joussaume, and F. David, Eds., Elsevier Science, 237-313.

Döös, K., and D. J. Webb, 1994: The Deacon cell and the other meridional cells in the Southern Ocean. J. Phys. Oceanogr., 24, 429-442.

Dutay, J.-C., and Coauthors, 2002: Evaluation of ocean model ventilation with CFC-11: Comparison of 13 global ocean models. Ocean Modell., 4, 89-120.

Fichefet, T., and M. A. Morales Maqueda, 1997: Sensitivity of a global sea ice model to the treatment of ice thermodynamics and dynamics. J. Geophys. Res., 102, 12 609-12 646.

Ganachaud, A., and C. Wunsch, 2000: Improved estimates of global ocean circulation, heat transport and mixing from hydrographic data. Nature, 408, 453-457.

- and - 2003: Large-scale ocean heat and freshwater transports during the World Ocean Circulation Experiment. $J$. Climate, 16, 696-705.

Garrett, C., and A. Tandon, 1997: The effects on water mass formation of surface and mixed layer time-dependence and entrainment fluxes. Deep-Sea Res. I, 44, 1991-2006.

_, K. Speer, and E. Tragou, 1995: The relationship between water mass formation and the surface buoyancy flux, with application to Phillips' Red Sea model. J. Phys. Oceanogr., 25, 1696-1705.

Gent, P. R., and J. C. McWilliams, 1990: Isopycnal mixing in ocean circulation models. J. Phys. Oceanogr., 20, 150-155. 
Godfrey, J. S., 1996: The effect of the Indonesian Throughflow on ocean circulation and heat exchange with the atmosphere: A review. J. Geophys. Res., 101, 12 217-12 238.

Goodman, P. J., 1998: The role of North Atlantic Deep Water formation in an OGCM's ventilation and thermohaline circulation. J. Phys. Oceanogr., 28, 1759-1785.

Gordon, A. L., 1986: Interocean exchange of thermocline water. $J$. Geophys. Res., 91, 5037-5046.

Haney, R. L., 1971: Surface thermal boundary condition for ocean circulation models. J. Phys. Oceanogr., 1, 241-248.

Hasumi, H., and N. Suginohara, 1999: Atlantic deep circulation controlled by heating in the Southern Ocean. Geophys. Res. Lett., 26, 1873-1876.

Hirst, A. C., and T. J. McDougall, 1998: Meridional overturning and dianeutral transport in a $z$-coordinate ocean model including eddy-induced advection. J. Phys. Oceanogr., 28, 1205-1223.

Huang, R. X., 1999: Mixing and energetics of the oceanic thermohaline circulation. J. Phys. Oceanogr., 29, 727-746.

- , and B. Qiu, 1994: Three-dimensional structure of the winddriven circulation in the subtropical North Pacific. J. Phys. Oceanogr., 24, 1608-1622.

Iudicone, D., 2007: The role of Southern Ocean in the global thermohaline circulation inferred from an OGCM. Ph.D. thesis, Université de la Bretagne Occidentale, 206 pp.

-, K. B. Rodgers, R. Schopp, and G. Madec, 2007: An exchange window for the injection of Antarctic Intermediate Water into the South Pacific. J. Phys. Oceanogr., 37, 31-49.

—, G. Madec, and T. J. McDougall, 2008a: Water-mass transformations in a neutral density framework and the key role of light penetration. J. Phys. Oceanogr., 38, 1357-1376.

- S. Speich, G. Madec, and B. Blanke, 2008b: The global conveyor belt from a Southern Ocean perspective. J. Phys. Oceanogr., 38, 1401-1425.

Jackett, D. R., and T. J. McDougall, 1997: A neutral density variable for the world's oceans. J. Phys. Oceanogr., 27, 237-263.

Josey, S. A., E. C. Kent, and P. K. Taylor, 1999: New insights into the ocean heat budget closure problem from analysis of the SOC air-sea flux climatology. J. Climate, 12, 2856-2880.

Karsten, R. H., and J. Marshall, 2002: Constructing the residual circulation of the ACC from observations. J. Phys. Oceanogr., 32, 3315-3327.

Karstensen, J., and D. Quadfasel, 2002: Formation of Southern Hemisphere thermocline waters: Water mass conversion and subduction. J. Phys. Oceanogr., 32, 3020-3038.

Klinger, B. A., S. Drijfhout, J. Marotzke, and J. R. Scott, 2003: Sensitivity of basin-wide meridional overturning to diapycnal diffusion and remote wind forcing in an idealized AtlanticSouthern Ocean geometry. J. Phys. Oceanogr., 33, 249-266.

,,--- , and — , 2004: Remote wind-driven overturning in the absence of the Drake Passage effect. J. Phys. Oceanogr., 34, 1036-1049.

Knutti, R., J. Flückiger, T. F. Stocker, and A. Timmermann, 2004: Strong hemispheric coupling of glacial climate through freshwater discharge and ocean circulation. Nature, 430, 851-856.

Large, W. G., and A. J. G. Nurser, 2001: Ocean surface water mass transformation. Ocean Circulation and Climate: Observing and Modelling the Global Ocean, G. Siedler, J. Church, and J. Gould, Eds., International Geophysics Series, Vol. 77, Academic Press, 317-336.

Macdonald, A. M., and C. Wunsch, 1996: An estimate of global ocean circulation and heat fluxes. Nature, 382, 436-439.

Madec, G., P. Delecluse, M. Imbard, and C. Lévy, 1998: OPA 8.1
Ocean General Circulation Model reference manual. Notes Techniques du Pôle de Modélisation 11, Institut Pierre Simon Laplace, $91 \mathrm{pp}$.

Manizza, M., C. Le Quéré, A. J. Watson, and E. T. Buitenhuis, 2005: Bio-optical feedbacks among phytoplankton, upper ocean physics, and sea-ice in a global model. Geophys. Res. Lett., 32, L05603, doi:10.1029/2004GL020778.

Marsh, R., 2000: Cabbeling due to isopycnal mixing in isopycnic coordinate models. J. Phys. Oceanogr., 30, 1757-1775.

— A. J. G. Nurser, A. P. Megann, and A. L. New, 2000: Water mass transformation in the Southern Ocean of a global isopycnic coordinate GCM. J. Phys. Oceanogr., 30, 1013-1045.

Marshall, J. C., and A. J. G. Nurser, 1992: Fluid dynamics of oceanic thermocline ventilation. J. Phys. Oceanogr., 22, 583-595.

- and T. Radko, 2003: Residual-mean solutions for the Antarctic Circumpolar Current and its associated overturning circulation. J. Phys. Oceanogr., 33, 2341-2354.

— A. J. G. Nurser, and R. G. Williams, 1993: Inferring the subduction rate and period over the North Atlantic. J. Phys. Oceanogr., 23, 1315-1329.

—, D. Jamous, and J. Nilsson, 1999: Reconciling thermodynamic and dynamic methods of computation of water-mass transformation rates. Deep-Sea Res. I, 46, 545-572.

, E. Shuckburgh, H. Jones, and C. Hill, 2006: Estimates and implications of surface eddy diffusivity in the Southern Ocean derived from tracer transport. J. Phys. Oceanogr., 36, 1806-1821.

McDougall, T. J., 1987: Neutral surfaces. J. Phys. Oceanogr., 17, 1950-1964.

Nurser, A. J. G., R. Marsh, and R. G. Williams, 1999: Diagnosing water mass formation from air-sea fluxes and surface mixing. J. Phys. Oceanogr., 29, 1468-1487.

Orsi, A. H., T. Whitworth III, and W. D. Nowlin Jr., 1995: On the meridional extent and fronts of the Antarctic Circumpolar Current. Deep-Sea Res. I, 42, 641-673.

— S. S. Jacobs, A. L. Gordon, and M. Visbeck, 2001: Cooling and ventilating the Abyssal Ocean. Geophys. Res. Lett., 28, 2923-2926.

Rahmstorf, S., and M. H. England, 1997: Influence of Southern Hemisphere winds on North Atlantic Deep Water flow. J. Phys. Oceanogr., 27, 2040-2054.

Rintoul, S. R., and M. H. England, 2002: Ekman transport dominates local air-sea fluxes in driving variability of Subantarctic Mode Water. J. Phys. Oceanogr., 32, 1308-1321.

_ C. Hughes, and D. Olbers, 2001: The Antarctic circumpolar system. Ocean Circulation and Climate: Observing and Modelling the Global Ocean, G. Siedler, J. Church, and J. Gould, Eds., Academic Press, 271-302.

Rio, M.-H., and F. Hernandez, 2004: A mean dynamic topography computed over the World Ocean from altimetry, in situ measurements, and a geoid model. J. Geophys. Res., 109, C12032, doi:10.1029/2003JC002226.

Robbins, P. E., and J. M. Toole, 1997: The dissolved silica budget as a constraint on the meridional overturning circulation of the Indian Ocean. Deep-Sea Res., 44, 879-906.

Roullet, G., and G. Madec, 2000: Salt conservation, free surface, and varying volume: A new formulation for ocean general circulation models. J. Geophys. Res., 105, $23927-23942$.

Schmitz, W. J., Jr., 1996a: On the World Ocean circulation. Vol. I: Some global features/North Atlantic circulation. Tech. Rep. WHOI-96-O3, Woods Hole Oceanographic Institute, 140 pp. , 1996b: On the World Ocean circulation. Vol. II: The Pacific 
and Indian Oceans/A global update. Tech. Rep. WHOI-9608, Woods Hole Oceanographic Institute, $237 \mathrm{pp}$.

Scott, J. R., and J. Marotzke, 2002: The location of diapycnal mixing and the meridional overturning circulation. J. Phys. Oceanogr., 32, 3578-3595.

Simmons, H. L., S. R. Jayne, L. C. St. Laurent, and A. J. Weaver, 2004: Tidally driven mixing in a numerical model of the ocean general circulation. Ocean Modell., 6, 245-263.

Sloyan, B. M., and S. R. Rintoul, 2000: Estimates of area-averaged diapycnal fluxes from basin-scale budgets. J. Phys. Oceanogr., 30, 2320-2341.

—, and —, 2001a: Circulation, renewal, and modification of Antarctic Mode and Intermediate Water. J. Phys. Oceanogr., 31, 1005-1030.

_ and - 2001b: The Southern Ocean limb of the global deep overturning circulation. J. Phys. Oceanogr., 30, 143-173.

Speer, K., and E. Tziperman, 1992: Rates of water mass formation in the North Atlantic Ocean. J. Phys. Oceanogr., 22, 93-104.

- S. R. Rintoul, and B. Sloyan, 2000: The diabatic Deacon cell. J. Phys. Oceanogr., 30, 3212-3222.

Stammer, D., and Coauthors, 2002: Global ocean circulation during 1992-1997, estimated from ocean observations and a general circulation model. J. Geophys. Res., 107, 3118, doi:10.1029/2001JC000888.

Stommel, H., 1979: Determination of water mass properties of water pumped down from the Ekman layer to the geostrophic flow below. Proc. Natl. Acad. Sci. USA, 76, 30513055.

Sverdrup, H. U., M. W. Johnson, and R. H. Fleming, 1942: The Oceans: Their Physics, Chemistry, and General Biology. Prentice Hall, 1087 pp.

Talley, L. D., 2003: Shallow, intermediate, and deep overturning components of the global heat budget. J. Phys. Oceanogr., 33, 530-560.

_ , J. L. Reid, and P. E. Robbins, 2003: Data-based meridional overturning streamfunctions for the global ocean. J. Climate, 16, 3213-3226.

Tandon, A., and C. Garrett, 1997: Water mass formation from thermodynamics: A framework for examining compatibility with dynamics. International WOCE Newsletter, No. 28, WOCE International Project Office, Southampton, United Kingdom, 666-667.

Taylor, H., A. L. Gordon, and E. Molinelli, 1978: Climate characteristics of the Antarctic Polar Front zone. J. Geophys. Res., 83, 4572-4578.

Timmermann, R., H. Goosse, G. Madec, T. Fichefet, C. Ethe, and V. Duliere, 2005: On the representation of high latitude processes in the ORCA-LIM global coupled sea ice-ocean model. Ocean Modell., 8, 175-201.

Toggweiler, J. R., and B. Samuels, 1993. Is the magnitude of the deep outflow from the Atlantic Ocean actually governed by Southern Hemisphere winds? The Global Carbon Cycle, M. Heimann, Ed., NATO ASI Series, Springer-Verlag, 303-331.
, and - 1998: On the ocean's large-scale circulation near the limit of no vertical mixing. J. Phys. Oceanogr., 28, 18321852.

Tomczak, M., and J. S. Godfrey, 1994: Regional Oceanography: An Introduction. Pergamon, $422 \mathrm{pp}$.

Toole, J. M., 1981: Sea ice, winter convection, and the temperature minimum layer in the Southern Ocean. J. Geophys. Res., 86, 8037-8047.

- and A. Warren, 1993: A hydrographic section across the subtropical south Indian Ocean. Deep-Sea Res., 40, 19732019.

Treguier, A. M., I. M. Held, and V. D. Larichev, 1997: On the parameterization of quasigeostrophic eddies in primitive equation ocean models. J. Phys. Oceanogr., 27, 567-580.

Trenberth, K. E., and J. M. Caron, 2001: Estimates of meridional atmosphere and ocean heat transports. J. Climate, 14, 34333443.

Tsujino, H., and N. Suginohara, 1999: Thermohaline circulation enhanced by wind forcing. J. Phys. Oceanogr., 29, 1506-1516.

Walin, G., 1982: On the relation between sea-surface heat flow and thermal circulation in the ocean. Tellus, 34, 187-195.

Warren, B. A., J. H. LaCasce, and P. E. Robbins, 1996: On the obscurantist physics of "form drag" in theorizing about the Circumpolar Current. J. Phys. Oceanogr., 26, 2297-2301.

Webb, D. J., and N. Suginohara, 2001: Vertical mixing in the ocean. Nature, 409, 37.

Wijffels, S., 2001: Ocean transport of fresh water. Ocean Circulation and Climate: Observing and Modelling the Global Ocean, G. Siedler, J. Church, and J. Gould, Eds., Academic Press, 475-488.

Williams, R. G., M. A. Spall, and J. C. Marshall, 1995: Does Stommel's mixed layer demon work? J. Phys. Oceanogr., 25, 30893102 .

Woods, 1985: Physics of thermocline ventilation. Coupled Ocean-Atmosphere Models, J. C. J. Nihoul, Ed., Elsevier, 543-590.

Wunsch, C., and R. Ferrari, 2004: Vertical mixing, energy, and the general circulation of the oceans. Annu. Rev. Fluid Mech., 36, 281-314.

You, Y., 1998: Dianeutral mixing and transformation of Antarctic Intermediate Water in the Indian Ocean. J. Geophys. Res., 103, 30 941-30 972.

_ 2002: Quantitative estimate of Antarctic Intermediate Water contributions from the Drake Passage and the southwest Indian Ocean to the South Atlantic. J. Geophys. Res., 107, 3031, doi:10.1029/2001JC000880.

_, T. J. McDougall, and R. W. Schmitt, 1995: Dianeutral motion, water-mass conversion, and nonlinear effects on the density ratio in the Pacific thermocline. J. Phys. Oceanogr., 25, 1891-1904.

Zhang, H.-M., and L. D. Talley, 1998: Heat and buoyancy budgets and mixing rates in the upper thermocline. J. Phys. Oceanogr., 28, 1961-1978. 